\title{
əIntensification and Maintenance of a Double Warm-Core Structure in Typhoon Lan (2017) Simulated by a Cloud-Resolving Model $\mathscr{O}$
}

\author{
Satoki Tsujino, ${ }^{\mathrm{a}, \mathrm{f}}$ KAZuhisa Tsuboki, ${ }^{\mathrm{b}}$ Hiroyuki Yamada,,${ }^{\mathrm{c}}$ TAdAyasu Ohigashi, ${ }^{\mathrm{d}}$ Kosuke Ito, ${ }^{\mathrm{c}}$ And \\ NORIO NAGAHAMA ${ }^{\mathrm{e}}$ \\ ${ }^{a}$ Department of Atmospheric Sciences, National Taiwan University, Taipei, Taiwan \\ ${ }^{\mathrm{b}}$ Institute for Space-Earth Environmental Research, Nagoya University, Nagoya, Aichi, Japan \\ ${ }^{\mathrm{c}}$ Faculty of Science, University of the Ryukyus, Nishihara, Okinawa, Japan \\ ${ }^{\mathrm{d}}$ National Research Institute for Earth Science and Disaster Resilience, Tsukuba, Ibaraki, Japan \\ ${ }^{\mathrm{e}}$ Meisei Electric Co., Ltd., Isesaki, Gunma, Japan
}

(Manuscript received 16 February 2020, in final form 22 November 2020)

\begin{abstract}
Knowledge of the development and maintenance processes of double warm cores in tropical cyclones is important for full understanding of the dynamics of storm intensity changes. During its mature stage, Typhoon Lan (2017) had a clear double warm-core structure, which was observed by dropsondes. In this study, to investigate the intensification and maintenance of the double warm-core structure, a numerical simulation of the storm is performed with a cloud-resolving model and verified by dropsonde and satellite observations. A potential temperature budget and backward trajectories are diagnosed to examine intensification and maintenance processes in the simulated eye. The budget analysis indicates that, during the most rapidly intensifying stage, a double warm core is enhanced by axisymmetric subsidence warming in the eye. In the mature stage, upper-core warming is mostly canceled by ventilation due to vertical wind shear, but the lower core continues to warm by asymmetric advection, possibly associated with dynamical instability in the eyewall. The results raise a topic of interest: it is difficult to fully explain the axisymmetric subsidence warming process during the most rapidly intensifying stage by the dynamical response in an axisymmetric balanced vortex. The back-trajectory analysis indicates that the air mass associated with the subsidence is partly induced by inward acceleration in subgradient regions (unbalanced processes) in the eyewall.
\end{abstract}

KEYWORDS: Hurricanes/typhoons; Tropical cyclones; Mesoscale models; Nonhydrostatic models

\section{Introduction}

In the eye region, tropical cyclones (TCs) exhibit a positive air temperature anomaly, relative to the environmental field, called a warm core. The warm core is closely linked to the central pressure and maximum wind speed of the storm via the thermal wind relationship (e.g., Emanuel 1986; Holland 1997). In particular, the structure of the warm anomaly corresponds to a decrease of mass owing to the expansion of the air in the storm center. The decrease in the mass is associated with a decrease of the surface pressure in the storm center in accordance with the hydrostatic balance. Thus, the evolution of the TC warm core is related to storm intensity, and knowledge of the dynamics of warm-core evolution is important for full understanding of changes in storm intensity.

๖ Denotes content that is immediately available upon publication as open access.

Supplemental information related to this paper is available at the Journals Online website: https://doi.org/10.1175/JAS-D-200049.s1.

\footnotetext{
${ }^{\mathrm{f}}$ Current affiliation: Hokkaido University, Sapporo, Hokkaido, Japan.

Corresponding author: Satoki Tsujino, satoki@gfd-dennou.org
}

Idealized numerical experiments with fine-resolution atmospheric models have been conducted to investigate the dynamics of the warm core in TCs. Stern and Zhang (2013a,b) performed numerical experiments with idealized vortices and diagnosed the potential temperature budget and air parcel trajectories of TC warm cores. On the basis of their analysis, they suggested that after the start of rapid intensification, the warm core is intensified in the middle troposphere by potentialtemperature advection. In particular, they found that the horizontal eddy component of the advection, which is associated with nonaxisymmetric flows of a wavenumber- 1 feature, is dominant in the early stage of rapid intensification. They also found that in the latter portion of rapid intensification, vertical advection of potential temperature due to axisymmetric subsidence was dominant in warming the midlevel eye. Then, during the quasi-steady stage, the warming tendency in the eye contributed by the mean vertical advection cancels the cooling contributed by subgrid-scale horizontal diffusion. Their findings suggest, therefore, that the warming process in the eye changes depending on the life stage of the storm.

Using a nonhydrostatic model, Ohno and Satoh (2015) performed a numerical experiment with an idealized vortex that revealed that the development of an upper-level warm core is caused by vertical advection of potential temperature in the storm eye associated with subsidence across the tropopause. In addition, the subsidence and core warming is mostly explained by the Sawyer-Eliassen response with an increase of inertial stability in the inner core, as the storm intensifies. Their result 
thus suggests that the lower stratosphere plays an important role in storm intensity changes.

On the basis of numerical simulation results and considering the hydrostatic balance, Zhang and Chen (2012) suggested that a warm core generated around the upper troposphere may be more likely to deepen the central pressure of a TC, compared with one generated around the middle troposphere. Chen and Zhang (2013) proposed that convective bursts in the inner-core region may play an important role in the formation of the warm core around the upper troposphere. In contrast, Stern and Zhang (2016), who documented the warm-core structure and structural changes of Hurricane Earl (2010) using multiple aircraft and dropsonde observations throughout the life time of the storm, found no relationship between the height of the warm core and storm intensity or intensity changes. Moreover, they showed that the maximum warm-core height depends on the reference profile used for environmental temperature around the storm.

Kieu et al. (2016) conducted a numerical experiment with an idealized vortex to investigate the development of a double warm-core structure and indicated that the upper warm core at the level of 200 to $100 \mathrm{hPa}$ can form by advection of the higher potential temperature of the lower stratosphere in association with inflow into the storm's eye near the tropopause. This lower-stratosphere inflow is generated by radiative cooling in upper-level clouds associated with outflow from the eyewall. In particular, the upper-level inflow expands to the storm's outer core. This result suggests that enhancement of the upper warm core can be influenced by the circulation not only in the eye and eyewall, but also in the outer-core region through radiative processes. Kieu et al. (2016) also suggested that many typhoons over the western North Pacific may have a double warm core. The maximum height of the warm core, as well as the warm core's role in storm intensification and its formation dynamics, remains an important topic in TC studies.

Although numerical simulation is a powerful tool for obtaining a full understanding of warm-core evolution, it is difficult to verify simulation results because in situ observations (such as with dropsondes) of the inner-core structure of TCs are lacking. In particular, in situ observations of typhoon centers obtained in the western North Pacific are limited to special field campaigns such as Impact of Typhoons on the Ocean in the Pacific (e.g., D'Asaro et al. 2014) since operational reconnaissance by the United States ceased in 1987. In 2017, the Tropical CyclonesPacific Asian Research Campaign for Improvement of Intensity Estimations/Forecasts (T-PARCII) project (Yamada et al. 2018; Ito et al. 2018) conducted a field campaign using Japanese aircraft to investigate the mature stage of Typhoon Lan (2017). Typhoon Lan formed in the Philippine Sea on 15 October 2017 and then moved slowly northward (Fig. 1a). As estimated by the Japan Meteorological Agency (JMA), the central pressure of the typhoon rapidly deepened from 965 to $935 \mathrm{hPa}$ during the period from 1800 UTC 19 October to 1800 UTC 20 October 2017 (Fig. 1b), when the storm reached the mature stage. This intensity was maintained until 1200 UTC 21 October 2017. Although the storm intensity estimated by the Joint Typhoon Warning Center (JTWC) was slightly different from the JMA estimates, the most rapidly intensifying period was the same in both (Fig. 1b).
The T-PARCII aircraft penetrated the center of the mature typhoon at around 0600 UTC 21 October 2017 and deployed dropsondes that succeeded in capturing the dynamic and thermodynamic fields of the inner core, including near the typhoon center. The sounding-based temperature profiles showed that Typhoon Lan had a clear double warmcore structure (Yamada et al. 2018).

The purpose of this study is to elucidate the evolutionary dynamics of the double warm-core structure of Typhoon Lan (2017) during the most rapidly intensifying and mature stages. Simulation results, including the double warm-core structure, obtained by a numerical simulation of Typhoon Lan conducted with a nonhydrostatic atmospheric model with full physics are validated against available observations, including dropsondes during the T-PARCII campaign. To assess the warm-core evolution in the simulation results, a potential temperature budget and the backward trajectories of airmass parcels are examined.

\section{Methods}

\section{a. Model description and experimental design}

The numerical study of Typhoon Lan was conducted with the Cloud Resolving Storm simulator (CReSS 3.4.2), which is a three-dimensional, regional, compressible nonhydrostatic model (Tsuboki and Sakakibara 2002). CReSS uses a terrainfollowing coordinate system in the vertical and calculates the three-dimensional wind-velocity components, perturbation pressure, perturbation potential temperature, turbulent kinetic energy, and the mixing ratios of water vapor, cloud water, rain, cloud ice, snow, and graupel; it does not use cumulus parameterization. CReSS has been used to study many aspects of TCs (e.g., Akter and Tsuboki 2012; Tsuboki et al. 2015; Tsujino et al. 2017). Table 1 summarizes the model physics.

The model domain spanned $30.72^{\circ}$ in the zonal direction and $40.96^{\circ}$ in the meridional direction and was $28.8 \mathrm{~km}$ high (Fig. 1a). The horizontal grid spacing was uniformly $0.02^{\circ}$ in both the zonal and meridional directions, and a stretched vertical coordinate was used. The finest grid spacing was $200 \mathrm{~m}$ at the lowest level, and there were 55 levels. The integration period was from 0000 UTC 16 October to 1200 UTC 21 October 2017. In the present simulation, global analysis data (GA; JMA 2017) with a $0.5^{\circ}$ resolution, provided by the JMA, were used for the initial and boundary conditions. Note that typhoon structure in the GA data was modified by a bogus technique (JMA 2017). A spectral nudging technique was used to reduce the track error (Tsujino and Tsuboki 2020). Details of the simulation settings are provided in Table 2.

At the bottom boundary, sea surface temperature (SST) was given by a daily satellite-based objective analysis and linearly interpolated in time. An optimally interpolated (OI) SST data product created using microwave (MW) and infrared (IR) data (MW_IR OI SST, version 5.0) was used in the simulation (Gentemann et al. 2003, 2004, 2010). This SST dataset is produced daily using MW and IR radiation observed by satellites. Thus, the large SST cooling associated with intense TCs can be 

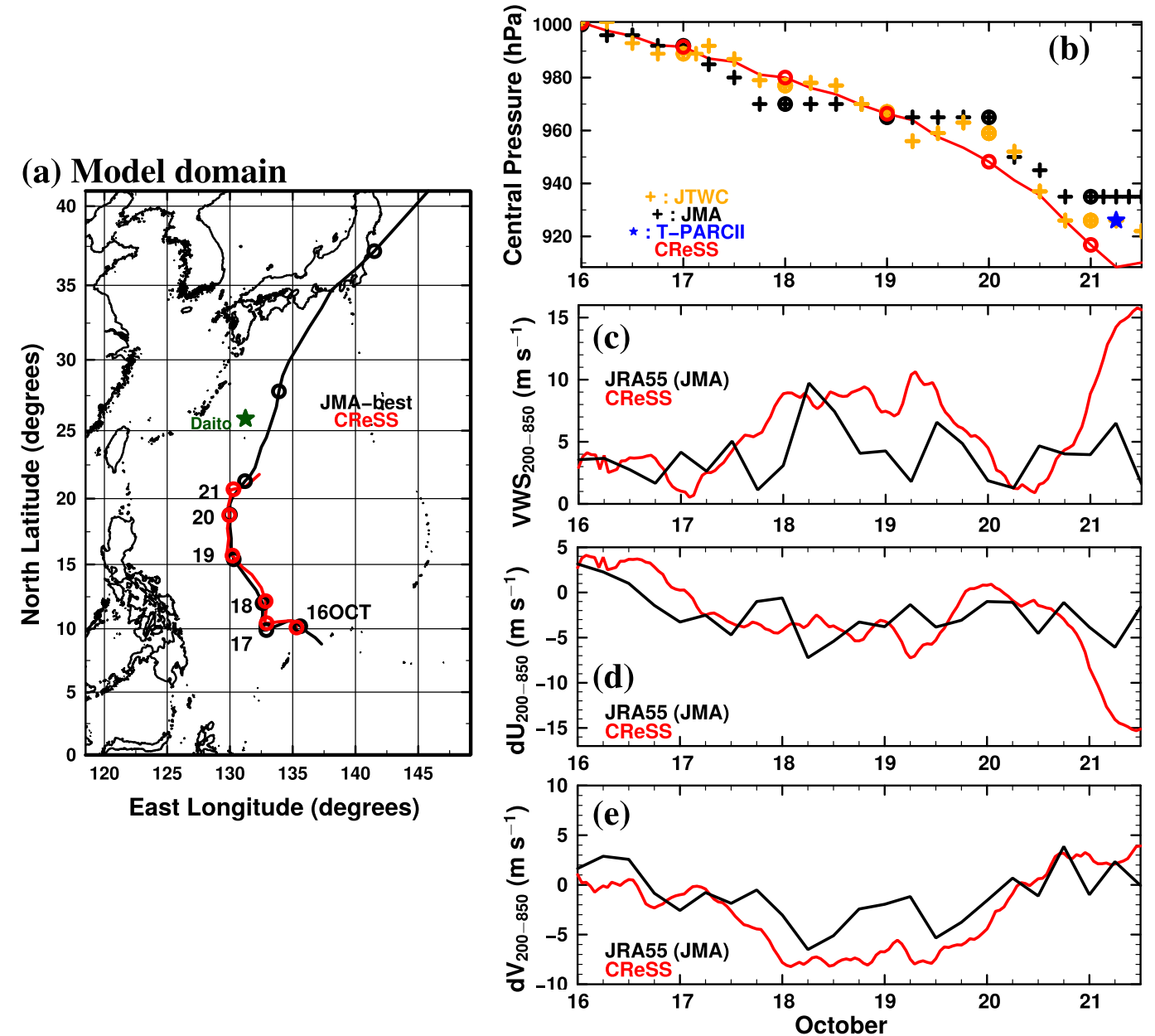

FIG. 1. (a) Track and (b) central pressure of Typhoon Lan (2017), (c) vertical shear of horizontal wind around the simulated storm, and (d) zonal and (e) meridional components of the vertical shear. Black line in (a) denotes the JMA best track. Black and yellow crosses in (b) correspond to best track data provided by the JMA and JTWC, respectively. The red lines denote simulated results. The model domain is shown in (a). The green star in (a) indicates the location of Minami-Daito Island, and the blue star in (b) indicates the sea level pressure observed by dropsonde in the storm eye during T-PARCII. The vertical shear values based on the JRA-55 are shown by the black lines in (c)-(e). The vertical shear and zonal $(d U)$ and meridional $(d V)$ components of the shear are defined as $\left(d U^{2}+d V^{2}\right)^{1 / 2},\left[U_{200}-U_{850}\right]$, and $\left[V_{200}-V_{850}\right]$, respectively. $U$ and $V$ are area averages of zonal and meridional wind components from the storm center to the $400 \mathrm{~km}$ radius. The subscripts 200 and 850 indicate the 200 and $850 \mathrm{hPa}$ levels in the vertical. Note that the JTWC estimated pressure at $0600 \mathrm{UTC} 21 \mathrm{Oct}$ was $925 \mathrm{hPa}$, which is close to the T-PARCII observation $(926 \mathrm{hPa})$.

approximately captured by these data. In the simulation, OI SST data of 17 October 2017 were used for the SST distribution at the initialization time (i.e., 0000 UTC 16 October 2017). ${ }^{1}$ Similarly, SST data of 18 October 2017 were used for the SST

\footnotetext{
${ }^{1}$ SST distribution on 1 day in this dataset can be composed of satellite observations obtained on that day and of observations made within 5 days. The SST data by an optimum interpolation calculation using the 5 days are provided on daily gridded data. Thus, we examined the sensitivity of the SST data within 1 day of the model initialization time and used the SST data for 17 October 2017 that resulted in the best simulated intensity change.
}

distribution at 0000 UTC 17 October in the simulation, and so on.

\section{b. Potential temperature budget}

Analysis of potential temperature budgets can reveal the evolutionary dynamics of a storm's eye (e.g., Stern and Zhang 2013a; Ohno and Satoh 2015). In the present study, the potential temperature $(\theta)$ budget equation was expressed in cylindrical coordinates as follows (Tsujino and Tsuboki 2020):

$$
\frac{\partial \bar{\theta}}{\partial t}=\mathrm{HADV}+\mathrm{VADV}+\mathrm{HEDDY}+\mathrm{VEDDY}+\mathrm{DIABQ},
$$


TABLE 1. Summary of the model physics.

\begin{tabular}{ll}
\hline \multicolumn{1}{c}{ Physics } & \multicolumn{1}{c}{ Description } \\
\hline Microphysics $^{\text {a }}$ & Explicit single-moment bulk scheme for condensation and cold rain (Lin et al. 1983) \\
Surface exchange & Aerodynamic bulk formula, from Kondo (1975) for ocean and from Louis et al. (1981) for land \\
Subgrid scale & 1.5-order closure with turbulent kinetic energy prediction (Deardorff 1980) \\
Shortwave and longwave radiation & Rapid Radiative Transfer Model (RRTM-G; 4.85) described in Mlawer et al. (1997) and \\
& Iacono et al. (2003) \\
\hline
\end{tabular}

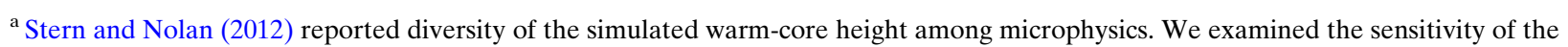
microphysics to the warm-core structure of Lan in supplemental material (see Fig. S3.1).

$$
\begin{gathered}
\text { HADV } \equiv-\bar{u} \frac{\partial \bar{\theta}}{\partial r}, \\
\text { VADV } \equiv-\bar{w} \frac{\partial \bar{\theta}}{\partial z}, \\
\text { HEDDY } \equiv-\frac{\partial r \overline{u^{\prime} \theta^{\prime}}}{r \partial r}, \\
\text { VEDDY } \equiv-\frac{\partial \rho_{0} \overline{w^{\prime} \theta^{\prime}}}{\rho_{0} \partial z},
\end{gathered}
$$

where HADV and VADV are horizontally and vertically advected potential temperature, respectively. HEDDY and VEDDY are horizontally and vertically resolved eddy terms (i.e., asymmetric advection), respectively. DIABQ indicates diabatic heating due to condensation, radiation, turbulent mixing (i.e., diffusion), and numerical diffusion. Overbar and prime denote the azimuthal average and the deviation from the azimuthal average, respectively. Radial $(r)$ and vertical $(z)$ wind components are denoted as $u$ and $w$, respectively. The parameter $\rho_{0}$ is the horizontally averaged air density. Then, $u^{\prime}$ is estimated from the storm-relative radial wind. The budget analysis was performed using model output at a 45-s interval (Table 2).

\section{c. Backward trajectory analysis}

To investigate core warming processes, Stern and Zhang (2013b) examined the origins of the air mass within the eye of idealized TCs by a backward trajectory analysis method. In the present study, backward trajectories of airmass particles were calculated by the method of Tsujino et al. (2017). Trajectory parcels were initially placed at locations at multiple levels within a radius of $35 \mathrm{~km}$ from the storm center. A time interval of $1 \mathrm{~s}$ for the time integration was used in the trajectory calculation with linearly interpolating the model output at a 45-s interval (Table 2). Parcels are placed at every model grid point for a given level that is located within $35 \mathrm{~km}$ of the storm center, and 613 parcels were placed at each level. The trajectories of the parcels were traced backward over the previous $12 \mathrm{~h}$. The levels at which the parcels were placed corresponded to the lower warm core $(z=2.1,2.4,2.8,3.1,3.5$, and $3.9 \mathrm{~km})$, the valley between cores $(z=7.1,7.5,7.9,8.3,8.7$, and $9.1 \mathrm{~km})$, and the upper warm core $(z=14.3,14.8,15.3$, and $15.9 \mathrm{~km})$.

\section{Evaluations of the simulation}

\section{a. Track and intensity}

We first validated the simulation results against available observations (Table 3 ). In the present study, the storm center was determined by the method in Braun (2002), which calculates the azimuthal variance of sea level pressure for 25 radial

\begin{tabular}{|c|c|}
\hline Feature & Description \\
\hline Model domain & $0^{\circ}-40.96^{\circ} \mathrm{N}, 118.5^{\circ}-149.22^{\circ} \mathrm{E}, 28.8 \mathrm{~km}($ vertical $)$ \\
\hline Grid spacing & $0.02^{\circ}$ (horizontal) and $200 \mathrm{~m}$ (lowest layer in the vertical) \\
\hline Initial and boundary & Global analysis data $\left(0.5^{\circ} \times 0.5^{\circ}\right)$ with 6-hourly output $($ JMA 2017$)$ \\
\hline Upper boundary & $\begin{array}{l}\text { A rigid lid with a sponge layer from } 18 \mathrm{~km} \text { height to the model top to prevent reflection of vertically } \\
\text { propagating waves }\end{array}$ \\
\hline Lateral boundary & Radiation of waves with constant phase velocity (e.g., Klemp and Wilhelmson 1978; Tsujino et al. 2017) \\
\hline Integration period & 0000 UTC 16 Oct to 1200 UTC 21 Oct 2017 \\
\hline Model output & Hourly (a 45-s interval for some analyses from 0000 UTC 19 Oct to 1200 UTC 21 Oct 2017) \\
\hline Terrain & $\begin{array}{l}\text { Shuttle Radar Topography Mission data with a horizontal resolution of } 30 \text { s (SRTM30) from the U.S. } \\
\text { Geological Survey (USGS) and U.S. National Aeronautics and Space Administration }\end{array}$ \\
\hline $\begin{array}{l}\text { SST } \\
\text { Spectral nudging }\end{array}$ & $\begin{array}{l}\text { Microwave optimally interpolated SST with a horizontal resolution of about } 9 \mathrm{~km} \text { (version } 5.0 \text { with MW and IR) } \\
\alpha=2.77778 \times 10^{-4} \mathrm{~s}^{-1}, f=1 \text { (Tsujino and Tsuboki 2020) } \\
\text { Nudging variables and scale: Horizontal velocities and larger than } 1500 \mathrm{~km}\end{array}$ \\
\hline Cloud radiation & $\begin{array}{l}\text { The radiative effects of ice are treated as in Ebert and Curry (1992) } \\
\text { Effective radius for } 50 \mu \mathrm{m} \text { ice crystals } \\
\text { Categories to calculate radiation: liquid and ice water contents } \\
\text { A fixed absorption coefficient of } 0.0602410 \mathrm{~m}^{2} \mathrm{~g}^{-1} \text { is used for liquid water } \\
\text { No mixing ratios of carbon dioxide and ozone are used }\end{array}$ \\
\hline
\end{tabular}
points between 2 and $50 \mathrm{~km}$ at each grid point within a radius of $65 \mathrm{~km}$ from the minimum sea level pressure location and

TABLE 2. Summary of the experimental design. 
TABLE 3. Validated elements and datasets used.

\begin{tabular}{lll}
\hline \hline \multicolumn{1}{c}{ Element } & \multicolumn{1}{c}{ Dataset } \\
\hline Track and central pressure & Best track data & Source \\
Cloud distributions & 85 GHz brightness temperature images & Naval Research Laboratory \\
Vertical wind shear & JRA-55 & JMA \\
Vertical profiles of temperature & Sondes & T-PARCII project (Ito et al. 2018; Yamada et al. 2018) \\
\hline
\end{tabular}

searches for the point of minimum variance. The simulated track was mostly consistent with the best track estimated by the JMA (Fig. 1a). The root-mean-square error (RMSE) of the simulated track was $79 \mathrm{~km}$. The small error was induced by the spectral nudging as reported by previous studies (e.g., Cha et al. 2011; Choi and Lee 2016; Tsujino and Tsuboki 2020). The simulated central pressure was also consistent with the JMA's estimation. In particular, the simulated intensification rate on 20 October 2017 was similar to both the JMA and JTWC best track data (Fig. 1b). On the other hand, the simulated central pressures were slightly lower than the central pressures in the best track data. The surface pressure at around 0600 UTC 21 October 2017, estimated from the lowest recorded vertical level ( $\sim 20$-m altitude) of a T-PARCII dropsonde in the eye, was $926 \mathrm{hPa}$ (blue star in Fig. 1b); this pressure is about $16 \mathrm{hPa}$ higher than the simulated central pressure at the same time. The simulated storm achieved the mature stage following its intensification.

Vertical wind shear around the storm began to rapidly decrease just before 1200 UTC 19 October 2017 (Fig. 1c), and during a period from 0000 to 2100 UTC 20 October 2017, vertical wind shear values were small. This result suggests that intensification after 1200 UTC 19 October 2017 predominantly resulted from internal storm processes. The evolution of the vertical shear in the simulation approximately followed that in the Japanese 55-year Reanalysis (JRA-55; Kobayashi et al. 2015) during the intensification period. On the other hand, the vertical shear in the simulation was larger than that in the JRA-55 during the mature stage. The large overestimation is associated with differences in the zonal component of the vertical shear rather than the meridional component (Figs. 1d,e).

\section{b. Horizontal structure of Typhoon Lan}

We used images captured by microwave satellites to verify the evolution and horizontal structure of the simulated inner core during the intensification period. In particular, the $85-\mathrm{GHz}$ band of the microwave satellites is useful for validating deep convection in the inner core (e.g., Cecil and Zipser 1999). Horizontal views of the brightness temperature observed by the $85-\mathrm{GHz}$ band (Figs. 2a-e) are compared with the brightness temperature simulated by the Satellite Data Simulator Unit (SDSU; Masunaga et al. 2010) with the model output (Figs. 2f-j). Before the most rapidly intensifying stage, active convection was observed in the eyewall and near the center of the storm (Figs. 2a-c). The eyewall convection had a slightly asymmetric structure in the observations. The asymmetric eyewall structure can also be seen in the simulation results, but the degree of asymmetry is more than that in the observations (Figs. $2 \mathrm{f}-\mathrm{h}$ ). On the other hand, the active convection near the storm center in the observation was not simulated. The eyewall in observed storm was located at a radius of $100 \mathrm{~km}$ from the storm center, similar to the simulation (the black lines in Figs. 2k and 2l).

In the observations, the active convection at the storm center was sustained for about $10 \mathrm{~h},{ }^{2}$ but eventually decayed (Figs. 2a-c), so that the storm center had less clouds (i.e., the eye cleared out). The observed eyewall gradually contracts in the intensification (the red, green, and blue lines in Fig. 2k). The distinct eyewall in the simulation gradually contracts from the start of storm's major intensification (the green and blue lines in Fig. 21).

During the most rapidly intensifying stage, the observed eyewall structure became more symmetric, and the eye size slightly decreased to a radius of $60 \mathrm{~km}$ as the eyewall gradually contracted (the blue line in Fig. 2k). The simulated eyewall gradually contracts and the eye size had a radius of $60 \mathrm{~km}$ during the most rapidly intensifying stage (the blue line in Fig. 21). During the mature stage, the symmetric eyewall structure was maintained in the observation (Fig. 2e). In contrast to the observation, an asymmetric structure in the simulated storm can be caused by the increase in the simulated vertical shear (Figs. 1c and 2j). Note that the width of the simulated eyewall was narrower than that of the observation from a satellite point of view. The difference can strongly depend on the microphysics in the model.

The evolution and structure of the inner core in the simulated storm could reasonably capture that of the observed storm, except for the absence of convection at the storm center before the start of the major intensifying stage and the more asymmetric eyewall structure during the mature stage for the simulated storm. Thus, we consider that the simulation during the most rapidly intensifying stage is reasonable for our analysis. On the other hand, the simulation results before the most rapidly intensifying stage and during the mature stage are still helpful for comparison with the inner-core evolution during the most rapidly intensifying stage.

\section{c. The simulated warm-core structure}

We used the T-PARCII dropsonde data to verify the simulated warm-core temperature. Figure 3 shows vertical distributions of temperature in the simulation and observation. The black solid line in Fig. 3a shows the temperature profile at the

\footnotetext{
${ }^{2}$ On the basis of 2.5 -min images in the Himawari- 8 satellite, the active convection at the storm center simultaneously formed when the eyewall clouds at the radius of $100 \mathrm{~km}$ formed (not shown). It indicates that the active convection is different from a remnant of the inner eyewall during an eyewall replacement cycle.
} 

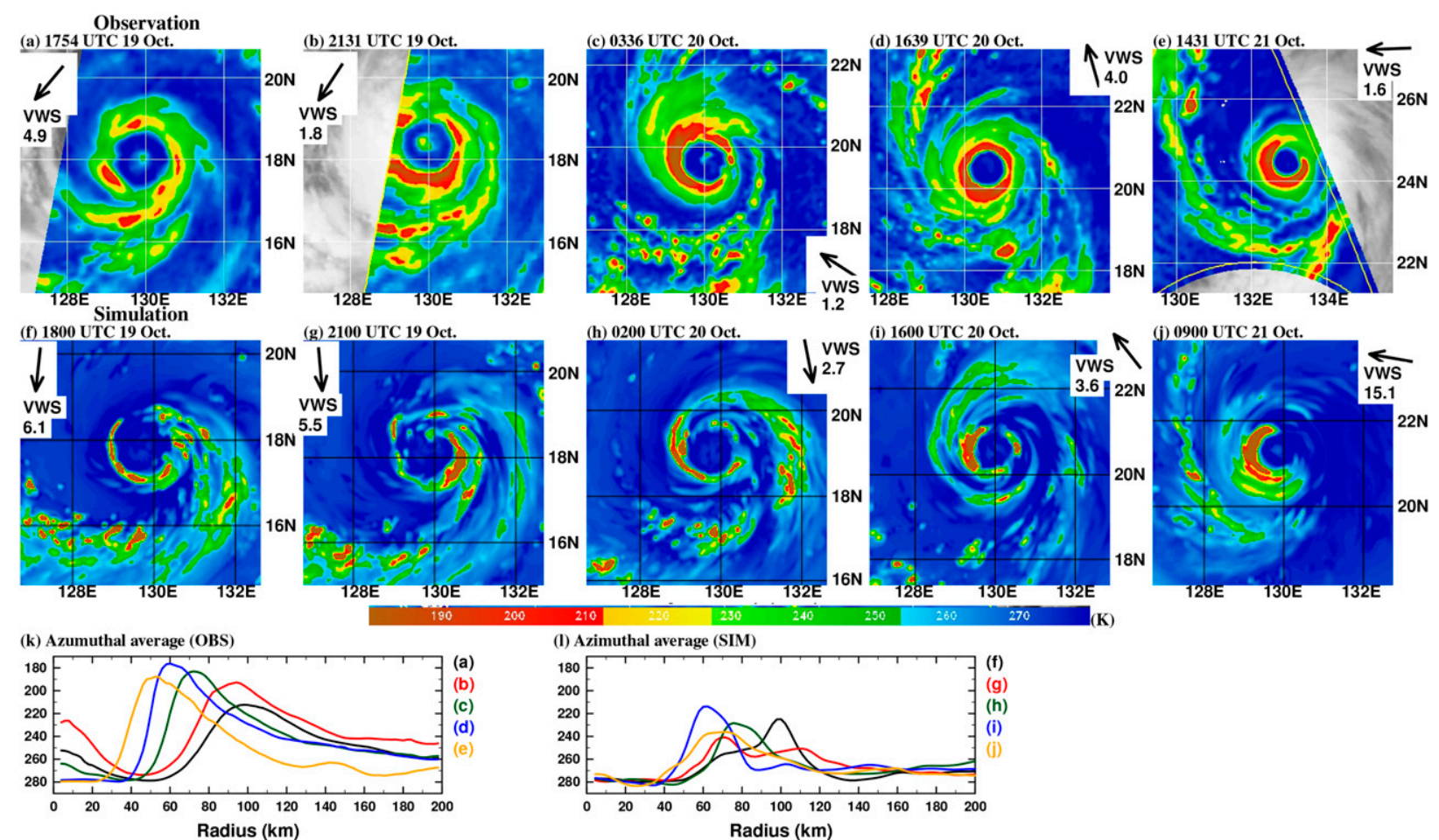

FIG. 2. Evolution of the storm structure in the observation and simulation. (a)-(e) Brightness temperature (K) captured by the $85 \mathrm{GHz}$ channels in microwave satellites. The microwave images are from the Naval Research Laboratory. (f)-(j) Brightness temperature (K) simulated by the model output. Direction and strength of the vertical shear are shown by vectors and values ( $\mathrm{m} \mathrm{s}^{-1}$ ), respectively. (k),(l) Radial profiles of azimuthally averaged brightness temperature at (a)-(e) and (f)-(j), respectively. The profiles in (k) were calculated from the microwave images with the method in Yang et al. (2013). The lowest resolution of the satellite images is $12.5 \mathrm{~km}$. To find common features in the inner-core structure between the simulation and observation, the times in (f)-(i) for the simulation were subjectively selected within a period of $\pm 3 \mathrm{~h}$ centered at each observation time, and (j) was subjectively selected within a period of $-3 \mathrm{~h}$ from the ending of the simulation (i.e., $1200 \mathrm{UTC} 21 \mathrm{Oct} 2017$ ).

grid point in the simulation where the profile was most similar to that obtained by dropsonde at the time closest to the dropsonde measurement. The most similar point was searched within a radius of $20 \mathrm{~km}$ from the storm center. The similarity was quantitatively estimated by calculating the lowest rootmean-square difference of the temperature profile between each grid point and the dropsonde data with the largest temperature anomaly below a height of $3 \mathrm{~km} .^{3}$ The range of the simulated warm-core temperature below a height of $4 \mathrm{~km}$ reasonably agrees with the corresponding dropsondes (Fig. 3b). In particular, the simulation was able to reproduce the inversion layer observed at the height of 2 to $3 \mathrm{~km}$. The local temperature peak above the inversion layer, however, is slightly weaker (by $2 \mathrm{~K}$ ) in the simulation than in the dropsonde results (Fig. 3b).

During T-PARCII, a balloon-borne radiosonde was launched from Minami-Daito Island at around 0600 UTC 21 October 2017, when the storm center was at a distance of about $400 \mathrm{~km}$

\footnotetext{
${ }^{3}$ According to one reviewer's comment, note that the method to compare temperature profiles between the dropsondes and the most similar point in the simulation has a potential caveat because it could favorably bias the comparison toward finding better agreement.
}

from the island (Fig. 1a). The azimuthally averaged temperature at a radius of $400 \mathrm{~km}$ from the storm center in the simulation agrees with the vertical distribution of the temperature observed above Minami-Daito Island at 0600 UTC 21 October 2017 (Fig. 3a; dashed red and black lines). Temperatures simulated at the radius of $400 \mathrm{~km}$ could be clearly distinguished from those at the storm center. Note that the dropsondes were not used in data-assimilation procedures in the GA that was used for the initial and boundary conditions in the simulation. Therefore, the simulated warm-core structure was generated solely by the dynamical and physical processes of CReSS, and the simulation results are useful for studying the evolution of the double warmcore structure in Typhoon Lan.

Moreover, above a height of $8 \mathrm{~km}$, the temperature anomalies in the dropsondes exhibited increases with height. The increases suggest another peak of a warm anomaly, distinct from the lower core. The simulated eye also exhibited a similar increase of temperature anomaly with height above a height of $10 \mathrm{~km}$. An upper-tropospheric peak of the warm anomaly was also observed by the Advanced Microwave Sounding Unit (AMSU; Fig. S1.1 in the online supplemental material). Note that the simulated warm anomaly in the upper troposphere could be overestimated. At around 0900 UTC 21 October 2017 , the simulated temperature anomaly at the storm center $\left(+9^{\circ} \mathrm{C}\right)$ 

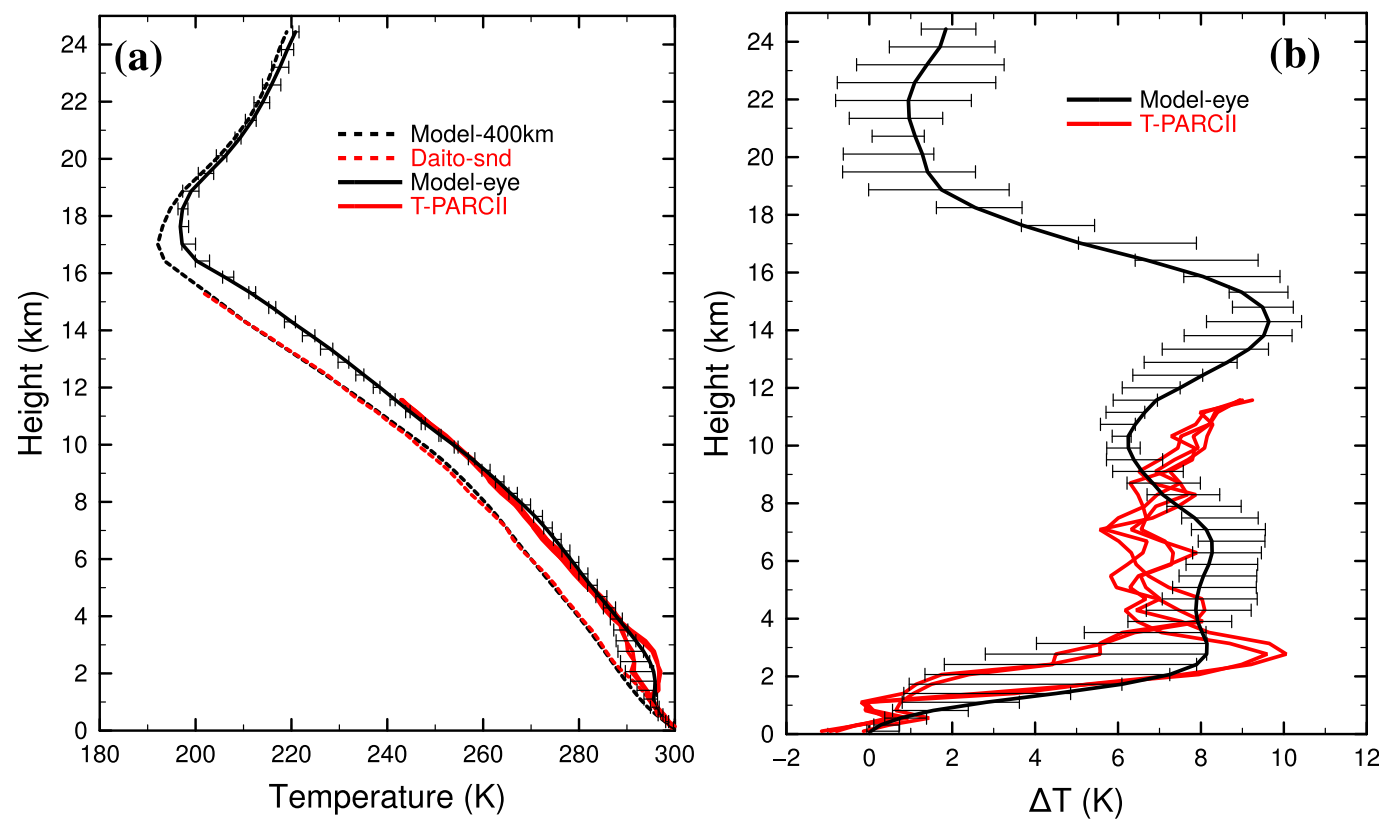

FIG. 3. Vertical profiles of (a) temperature and (b) temperature anomalies obtained by dropsondes (solid red lines) in the storm eye during T-PARCII at around 0600 UTC 21 Oct 2017 and at the grid point in the simulation (solid black line) where the profile was most similar to that obtained by dropsonde at the time closest to the dropsonde measurement (see details in the main text). The black and red dashed lines in (a) denote the sonde data at Minami-Daito Island (Fig. 1a) and the azimuthally averaged temperature profile at a radius of $400 \mathrm{~km}$ at the same time in the simulation, respectively. The anomalies of the dropsondes and simulation in (b) were calculated with the reference profiles at the Minami-Daito (red dashed line) and the $400 \mathrm{~km}$ radius (black dashed line), respectively. The whisker plots denote the minimum and maximum temperature within a radius of $20 \mathrm{~km}$ at each model level.

was higher than that $\left(+6^{\circ} \mathrm{C}\right)$ at the storm center observed by channel $8(55.5 \mathrm{GHz})$ in the AMSU satellite, which has a maximum amplitude of the weighting function at about $13 \mathrm{~km}$ altitude (Fig. S1.2). The higher temperature anomaly in the simulation can influence the overestimation of the central pressure in the simulation at around 0900 UTC 21 October 2017 (Fig. 1b).

Yamada et al. (2018) reported the spatial distribution of the dropsonde-based equivalent potential temperature $\left(\theta_{e}\right)$ near the inner-core region at around 0600 UTC 21 October 2017, and pointed out that the $\theta_{e}$ values of the observed Lan were clearly different between the lower and upper cores. In the observed lower core, $\theta_{e}$ was less than $358 \mathrm{~K}$, whereas in the observed upper core, it was greater than $370 \mathrm{~K}$. Near the inner core of the simulated Lan at 0600 UTC 21 October 2017 (Fig. 4), $\theta_{e}$ in the simulated eye is at a minimum $(<362 \mathrm{~K})$ at $4 \mathrm{~km}$ height, and above $4 \mathrm{~km}, \theta_{e}$ in the eye increases with height. At $12 \mathrm{~km}$ height in the eye, $\theta_{e}$ exceeds $374 \mathrm{~K}$, similar to the observation.

Moreover, $\theta_{e}$ in the observed upper core was similar to that in the eye near the sea surface, and both these high- $\theta_{e}$ regions were linked via relatively large $\theta_{e}$ in the eyewall updraft at radii of around 30 to $50 \mathrm{~km}$ (Yamada et al. 2018). Yamada et al. (2018) suggested that the air mass in the upper core may originate from the high- $\theta_{e}$ air mass in the eye boundary layer (EBL), because $\theta_{e}$ is an approximately conserved quantity.

\section{Evolution of the storm warm core}

The numerical simulation could reasonably reproduce the eyewall contraction and eye size during the most rapidly intensifying stage. Evolution of the simulated inner-core structure is examined in this section. Here, the simulated warm core is defined as the potential temperature anomaly from the azimuthally averaged potential temperature (referred to as $\theta_{\text {ref }}$ ) at a radius of $400 \mathrm{~km}$ from the storm center. ${ }^{4}$

Figure 5 shows the evolution of the potential temperature anomaly, $\theta-\theta_{\text {ref }}$, at the storm center in the simulation. A warm core formed in the $4-8 \mathrm{~km}$ layer at around $17-18$ October 2017 , and the warm core with $\theta-\theta_{\text {ref }}$ of 6-8 K was maintained for more than 1 day. The warm core became enhanced after 2100 UTC 19 October 2017, and the thickness of the warm anomaly layer rapidly increased during the most rapidly intensifying stage. During the same stage, the bottom height of the warm layer, defined as the height of a warm anomaly of $+10 \mathrm{~K}$, rapidly decreased from 6 to $1.5 \mathrm{~km}$, and the peak $\theta-\theta_{\text {ref }}$ value increased from 10 to $20 \mathrm{~K}$.

Concurrent the enhancement of this warm core, a second warm core began to enhance in the $12-16 \mathrm{~km}$ layer on around 2100 UTC 19 October 2017. The warm core that originated in

\footnotetext{
${ }^{4}$ The dependence of the results on the reference profile radius is examined in Fig. S2.1 of the supplemental material.
} 


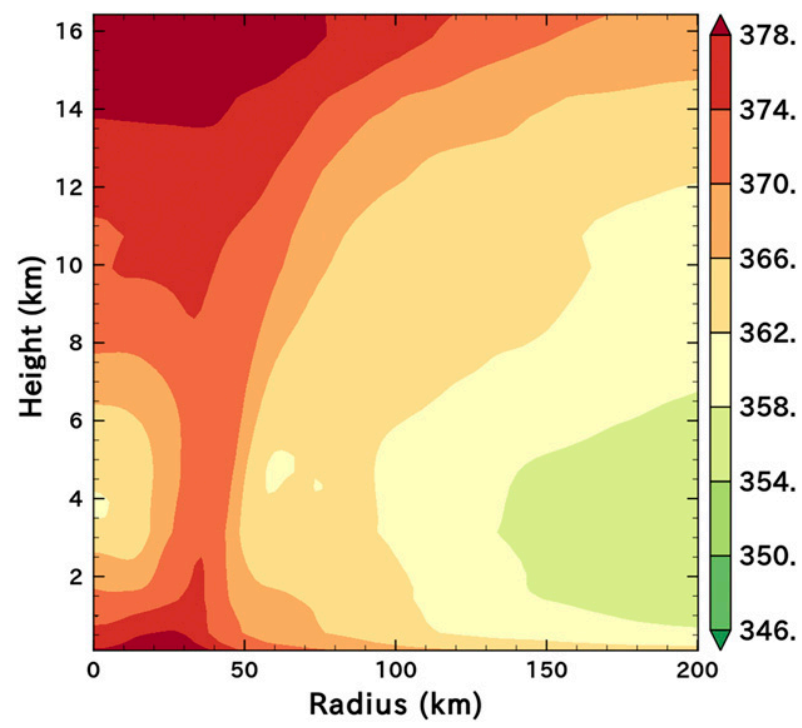

FIG. 4. Radius-height cross section of the azimuthally averaged equivalent potential temperature $(K)$ in the simulated Lan at 0600 UTC 21 Oct 2017.

the 4-8 km layer is thus called the "lower core," and the second warm core in the $12-16 \mathrm{~km}$ layer is called the "upper core." The upper core slightly expanded upward until 0900 UTC 20 October 2017, and became enhanced from 1200 UTC 20 October 2017 by downward expansion of the warm anomaly layer. As in the lower core, the amplitude of $\theta-\theta_{\text {ref }}$ in the warm layer increased from 10 to $20 \mathrm{~K}$. Of particular interest is the slight difference in the rate at which the central pressure decreased between before and after 1200 UTC 20 October 2017 (Fig. 1b); the central pressure decreased at a higher rate after than before 1200 UTC 20 October 2017. The high rate of the central pressure decrease may be associated with not only lower-core development but also upper-core development. The simulated storm had a clear double warm-core structure during the mature stage (i.e., after 0000 UTC 21 October 2017). We separate the storm life cycle into three $12 \mathrm{~h}$ periods, early and later stages (IS1 and IS2) of the most rapidly intensifying period and the mature stage (MS), as follows: IS1, 2100 UTC 19 October to 0900 UTC 20 October 2017; IS2, 1200 UTC 20 October to 0000 UTC 21 October 2017; and MS, 0000 to 1200 UTC 21 October 2017. In the IS1 period, the lower core had the downward expansion without the downward expansion of the upper core. In the IS2 period, both cores had the downward expansion. In the MS period, the upper core still had the downward expansion, but the lower core mostly maintained.

Figure 6 shows the evolution of the inner-core structure in the simulation. About 1 day prior to the start of IS1, the simulated storm already had double warm cores (Fig. 6a). The region of large $\theta-\theta_{\text {ref }}(>8 \mathrm{~K})$ was limited to within a radius of $20 \mathrm{~km}$ from the storm center. A weak vertical gradient of tangential wind corresponded to a weak radial gradient of potential temperature around the lower core via the thermal wind relationship. In IS1, the region of large $\theta-\theta_{\text {ref }}$ in the

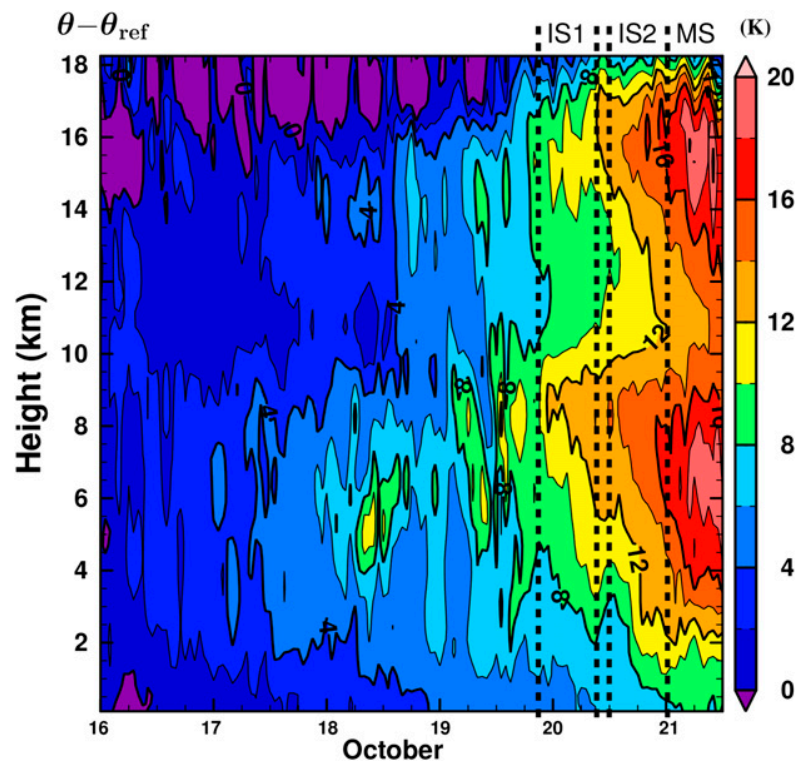

FIG. 5. Time evolution of the potential temperature anomaly at the storm center. The anomaly is defined as the departure of potential temperature at the storm center from the azimuthally averaged potential temperature $\left(\theta_{\text {ref }}\right)$ at the radius of $400 \mathrm{~km}$ from the center.

6-10 km layer expanded to a radius of $40 \mathrm{~km}$, and the upper core intensified between heights of 14 and $18 \mathrm{~km}$ (Fig. 6b). A relatively strong vertical tangential wind gradient was generated at around the same radius in the lower core. Concurrent with the intensification of the upper core, the tangential winds in the upper troposphere increased.

In IS2, warming through approximately all levels in the troposphere was exhibited in the eye (Fig. 6c). The warming caused the descending of the bottoms of the warm cores. The bottom of the lower core descended to a height of $1 \mathrm{~km}$. The downward expanded lower core was maintained in MS (Fig. 6d). As a result, a clear inversion layer became more pronounced around the simulated storm center at 0600 UTC 21 October 2017 (Fig. 3). Additionally, the warm regions expanded outward in IS2 (Fig. 6c). The upper core expanded outward, and its peak height decreased with increasing radius out to $50 \mathrm{~km}$. The upper core on the radius-height cross section (Fig. 6c) has a hat-like shape. Coincident with this hat shape, the tangential wind had a positive vertical gradient at radii of 20 to $50 \mathrm{~km}$ and heights of 10 to $14 \mathrm{~km}$. Consistent with the thermal wind relationship, the positive gradient region corresponded to a region with a positive radial gradient in potential temperature. This positive gradient region was also reported by Stern and Zhang (2013a).

\section{Potential temperature budget}

In this section, the potential temperature budget is analyzed to show the warming processes of the double warm-core structure in each of the three stages (IS1, IS2, and MS). Figure 7 shows the budget analysis results during IS1. At this stage, the simulated storm already has a clear warm core in the 
(a) $15 Z 18$ Oct

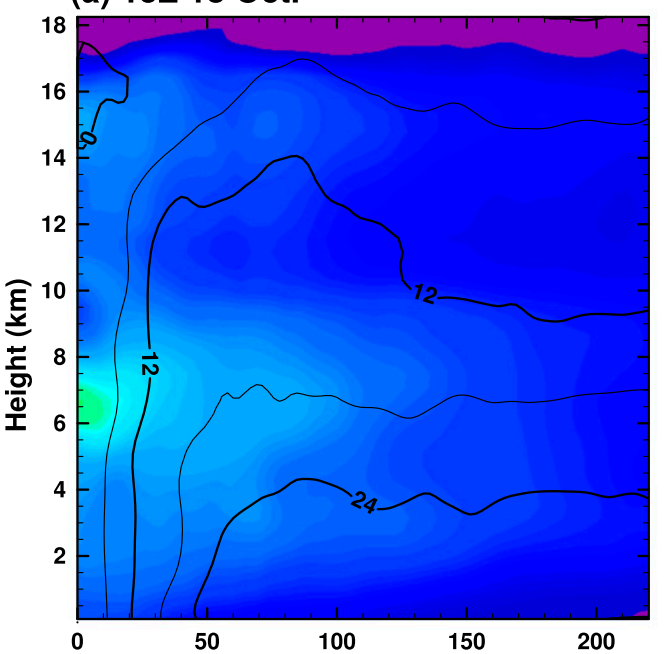

(c) $18 Z 20$ Oct.

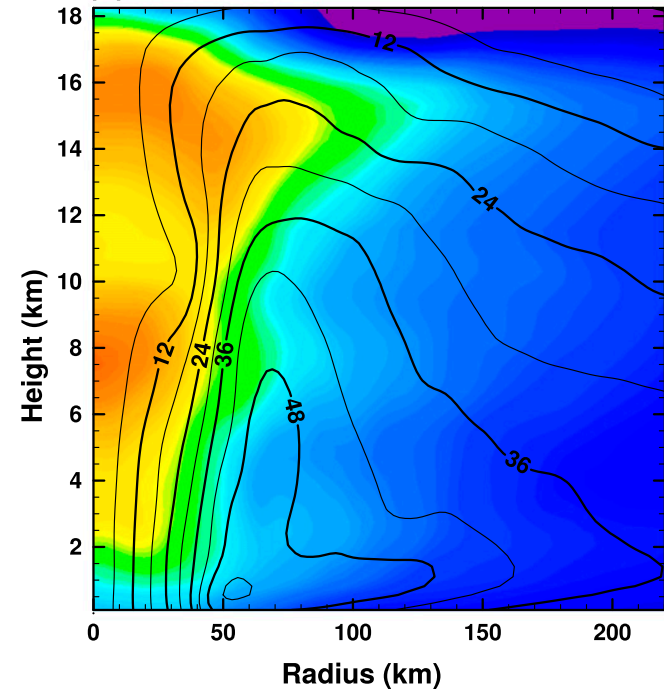

(b) $03 Z 20$ Oct.

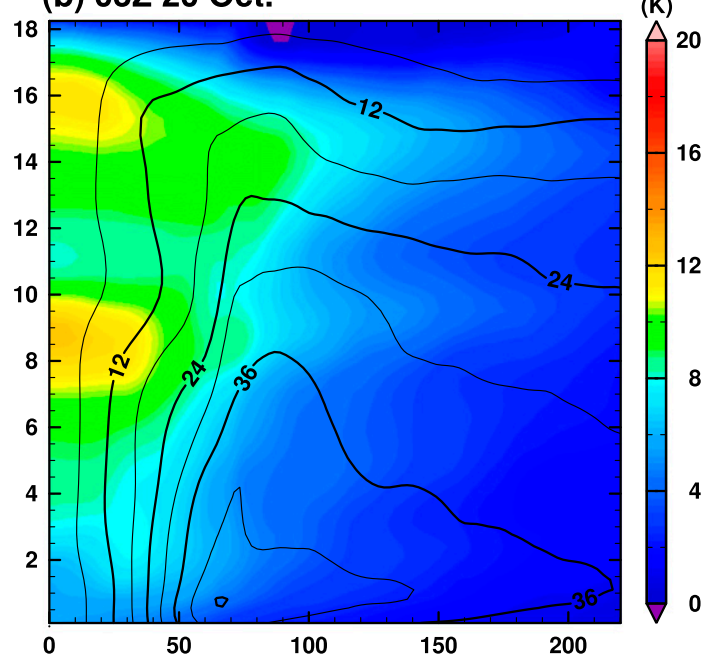

(d) $04 Z 21$ Oct.

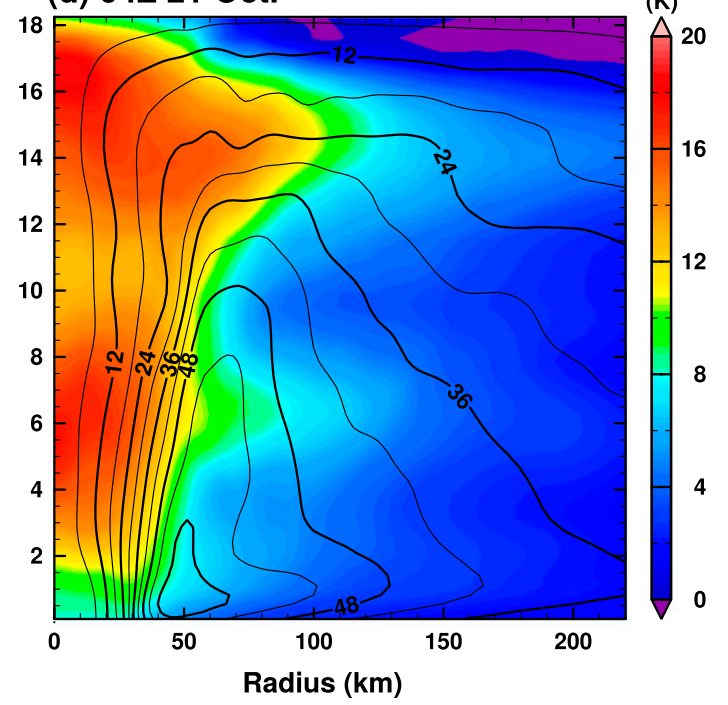

FIG. 6. Radius-height cross sections showing the inner-core structure of the simulated Lan at (a) 1500 UTC 18 Oct, (b) 0300 UTC 20 Oct, (c) 1800 UTC 20 Oct, and (d) 0400 UTC 21 Oct 2017 . The color scale denotes the azimuthally averaged potential temperature anomaly $(\mathrm{K})$. Contours denote the azimuthally averaged tangential wind $\left(\mathrm{m} \mathrm{s}^{-1}\right)$.

middle troposphere (6 to $10 \mathrm{~km}$ in height). Another peak of warm anomaly was also exhibited in the upper troposphere as shown in Fig. 5. Subsequently, all levels in the storm eye are warmed, in accordance with the actual change of $\bar{\theta}$ (Fig. 7a). A clear large potential temperature increase of more than $4 \mathrm{~K}$ is seen in the layer from 15 to $18 \mathrm{~km}$ within a radius of $40 \mathrm{~km}$. To check the accuracy of the budget analysis, the terms on the right-hand side of Eq. (1) were summed (Fig. 7b). Within the eye region, the actual change is nearly the same as the sum of those terms. This similarity between the actual change and the simulated change indicates that the budget analysis is reasonable to examine the warm-core warming processes in the eye. In contrast, there are large discrepancies in the eyewall above a height of $16 \mathrm{~km}$ and in the boundary layer outside of the eye, and these discrepancies are seen in IS2 and MS as well (Figs. 8b and $9 b)$.
The large warming in the upper layer at the height of $15-17 \mathrm{~km}$ (Fig. 7b) is induced mainly by advection of $\bar{\theta}$ caused by the axisymmetric subsidence of VADV (Fig. 7f), which resulted in the enhancement of the upper warm core. Large VADV is dominant at heights of 11 to $17 \mathrm{~km}$, but at heights of 11 to $13 \mathrm{~km}$, VADV is mainly cancelled by large cooling in DIABQ (Fig. 7c), which is induced by diffusion and evaporation associated with the thin midlevel cloud layer at $10 \mathrm{~km}$ height in the eye (not shown). In IS1, the eye temperature anomaly is still relatively weak. The large VADV in the 13 to $16 \mathrm{~km}$ height range is partly cancelled by cooling due to horizontal eddy transport (Fig. 7h), whereas the heating above $17 \mathrm{~km}$ height is mainly caused by DIABQ (Fig. 7c), which is primarily due to numerical diffusion (not shown). This effect is model-system dependent and is different in Stern and Zhang (2013a). 
(a) Actual change

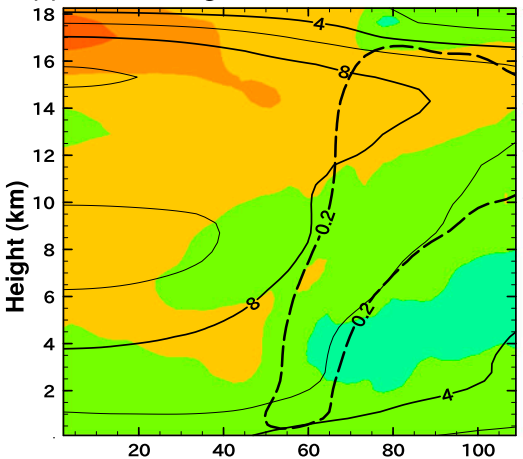

(d) Total advection (HADV+TADV)

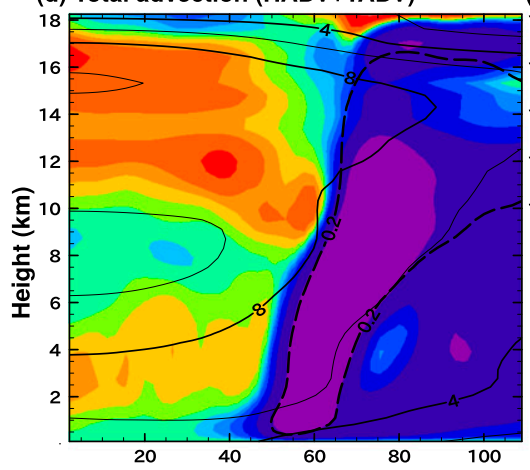

(g) Total eddy (HEDDY+VEDDY)
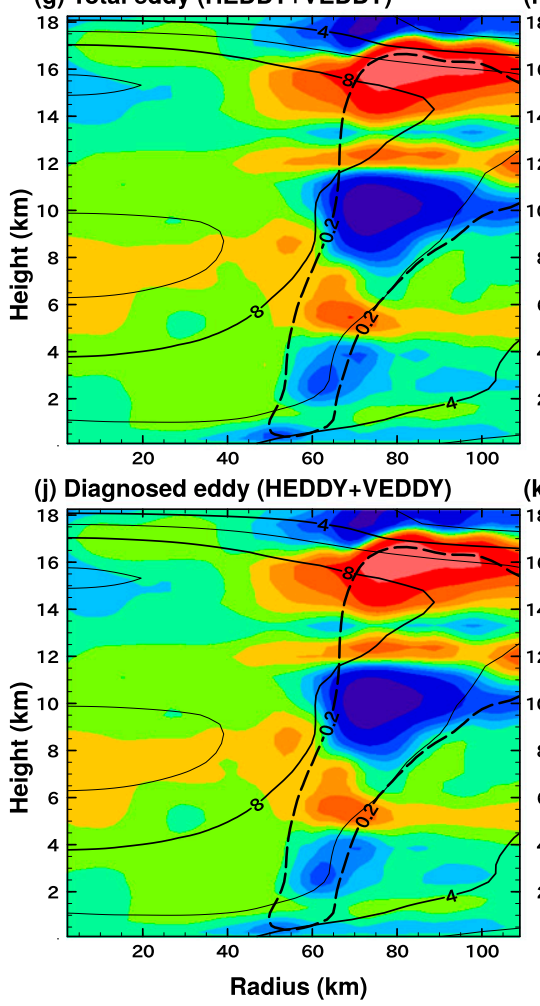

(b) Sum of RHS

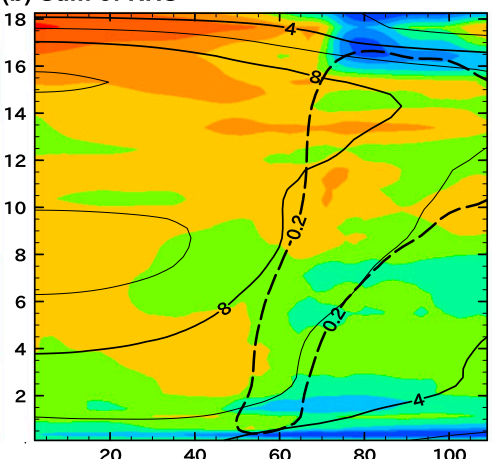

(e) Horizontal advection (HADV)

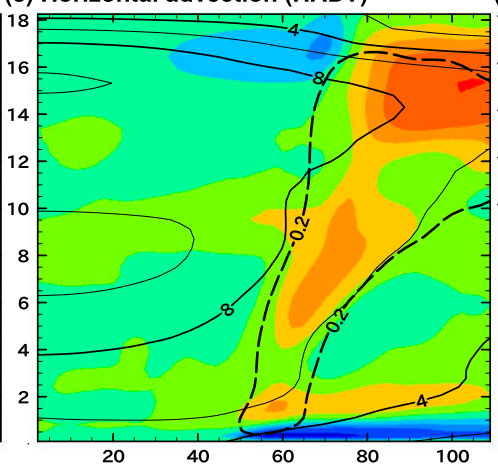

(h) Horizontal eddy (HEDDY)

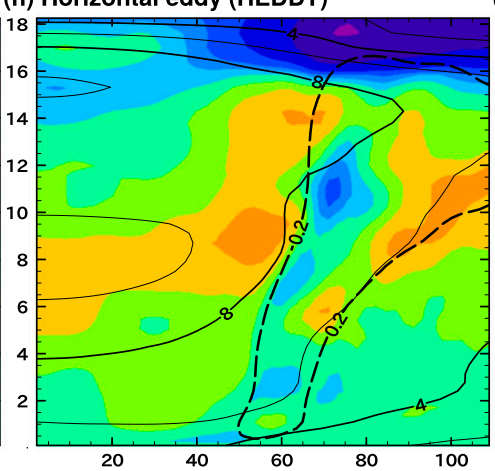

(k) Eliassen-response HADV+VADV

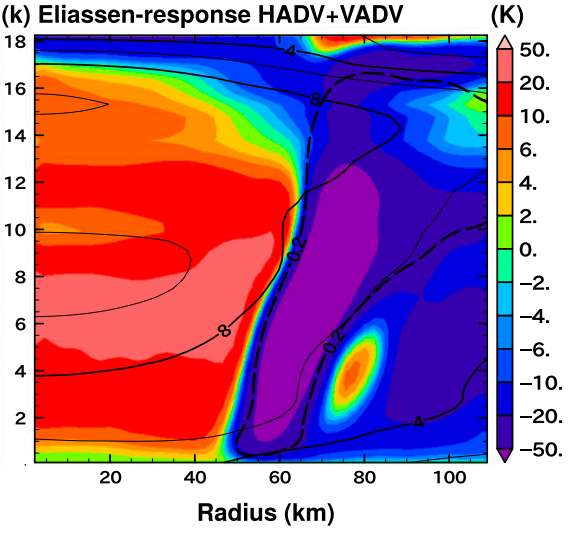

K) (c) Diabatic heating (DIABQ)

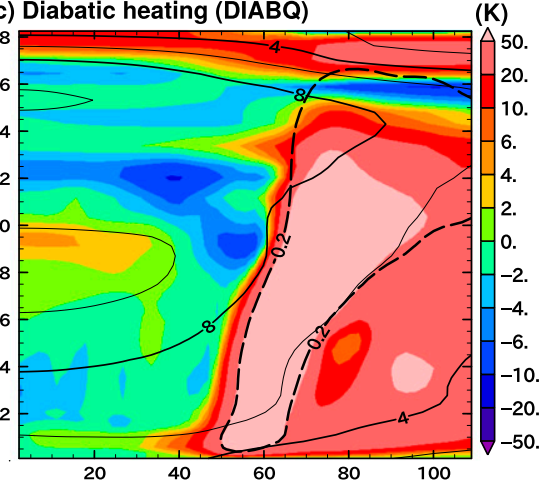

(f) Vertical advection (VADV)
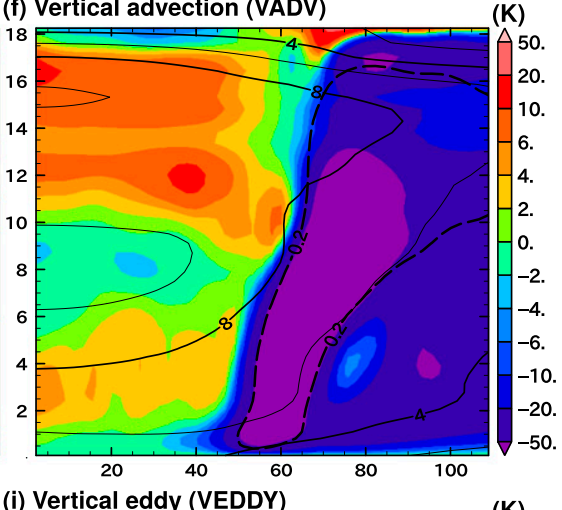

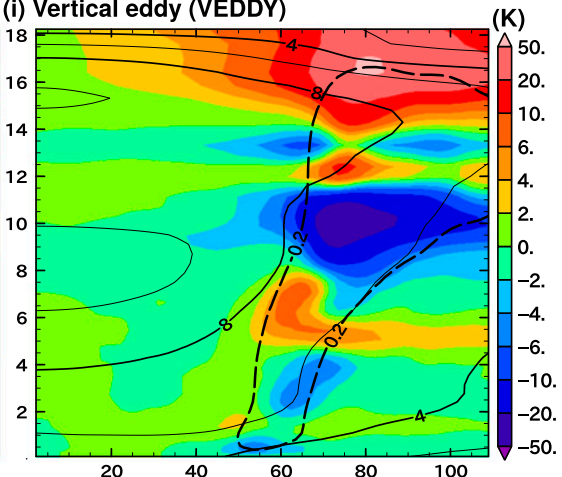

Radius (km)

100

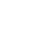

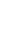


(a) Actual change

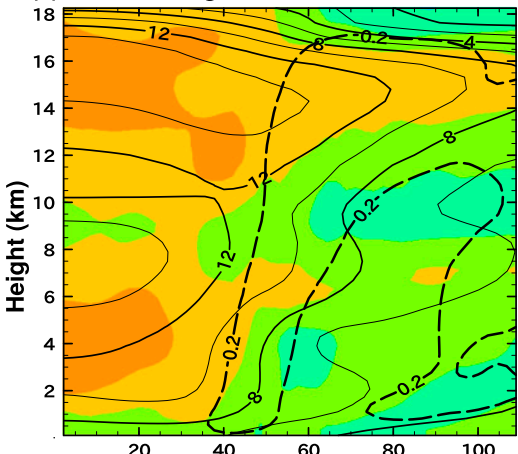

(d) Total advection (HADV+TADV)

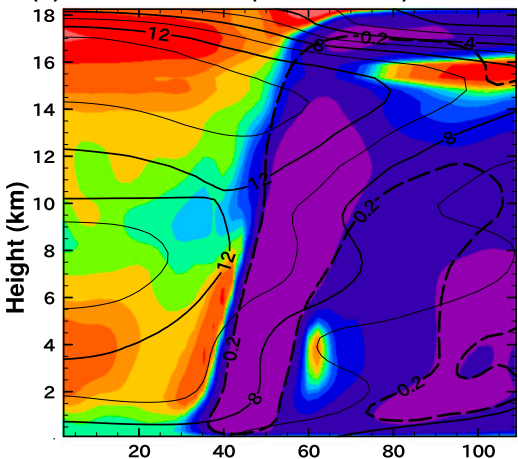

(g) Total eddy (HEDDY+VEDDY)

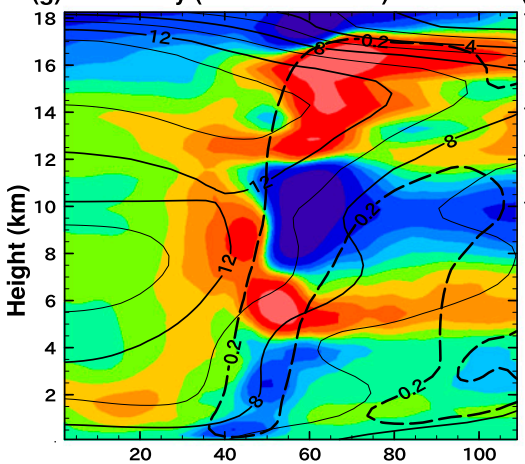

(j) Diagnosed eddy (HEDDY+VEDDY)

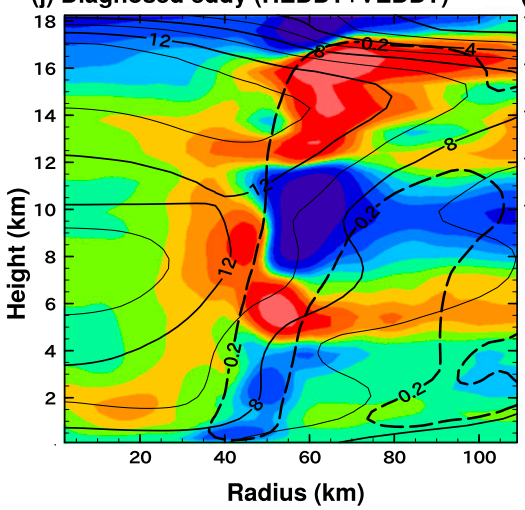

(b) Sum of RHS

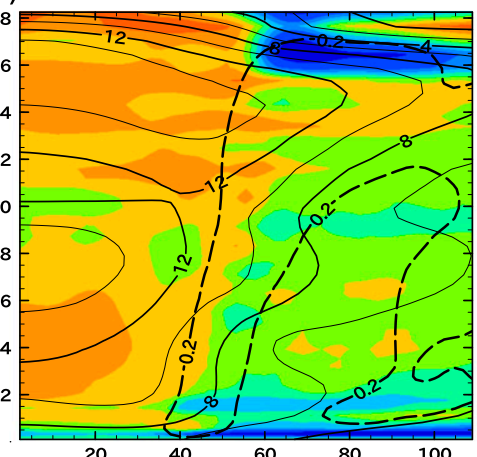

(e) Horizontal advection (HADV)

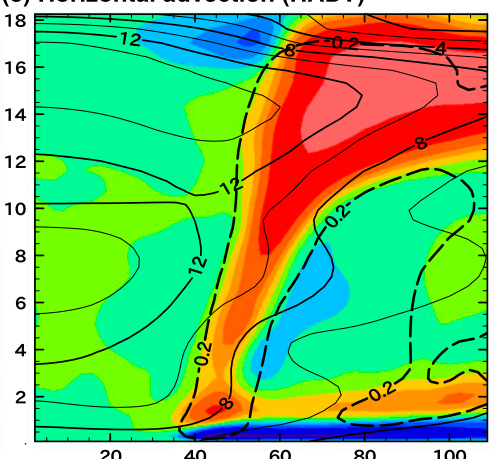

(h) Horizontal eddy (HEDDY)

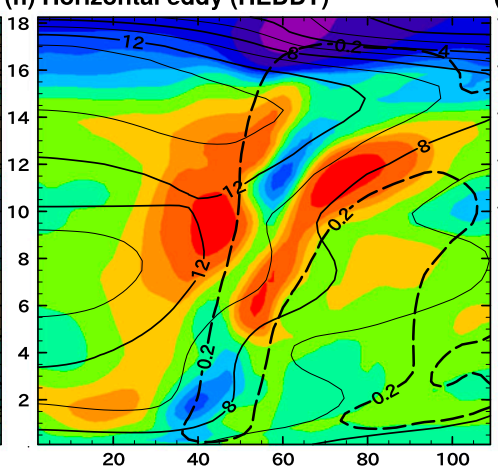

(k) Eliassen-response HADV+VADV

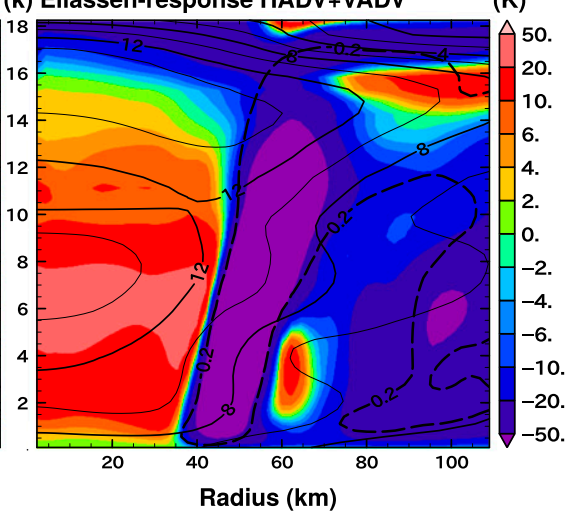

(c) Diabatic heating (DIABQ)

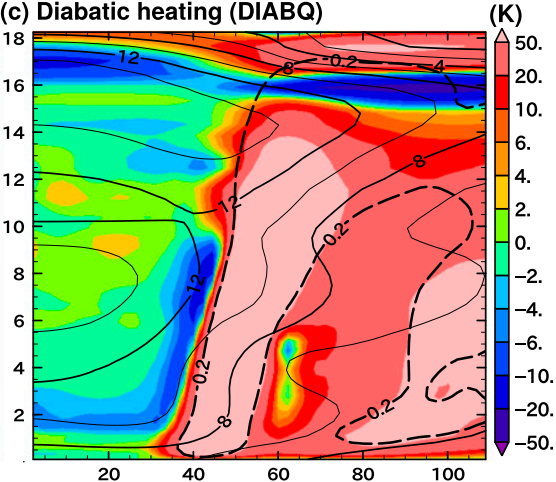

(f) Vertical advection (VADV)
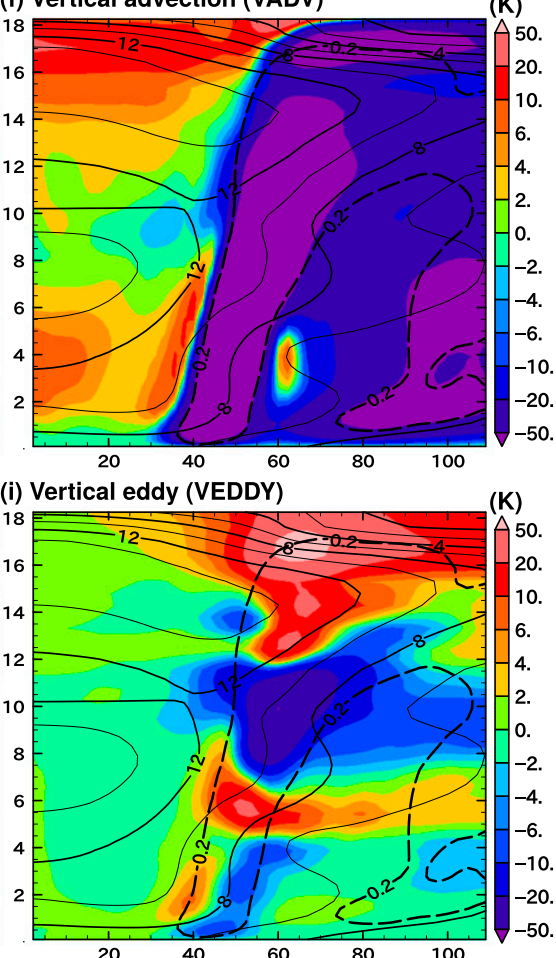

K)

Radius (km)

FIG. 8. As in Fig. 7, but at a later stage of intensification (1200 UTC 20 Oct to 0000 UTC 21 Oct 2017). 


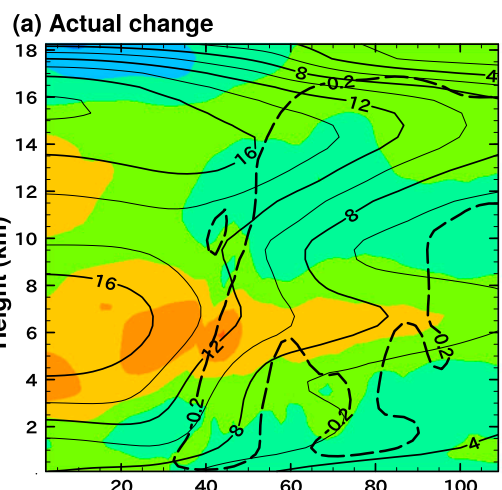

(b) Sum of RHS

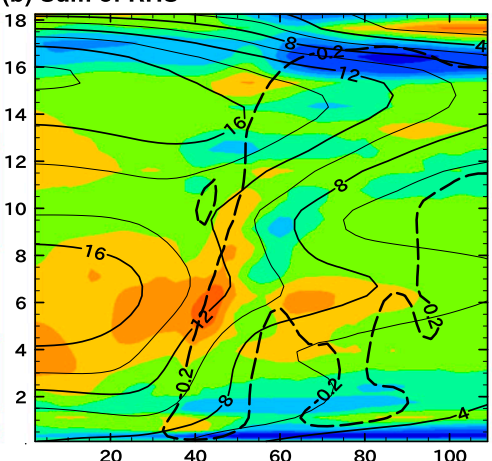

(d) Total advection (HADV+TADV)

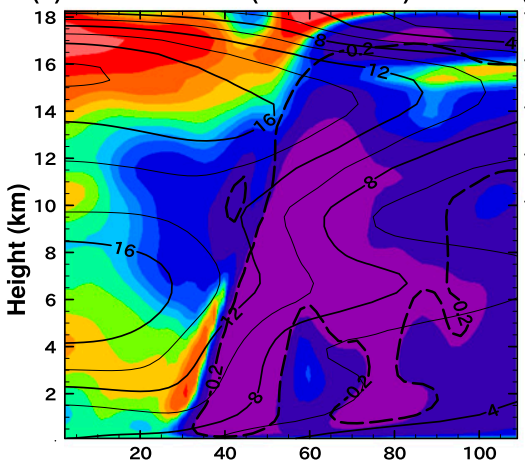

(g) Total eddy (HEDDY+VEDDY)

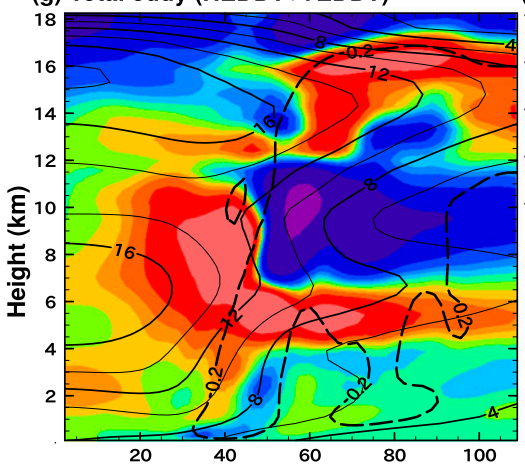

(j) Diagnosed eddy (HEDDY+VEDDY)

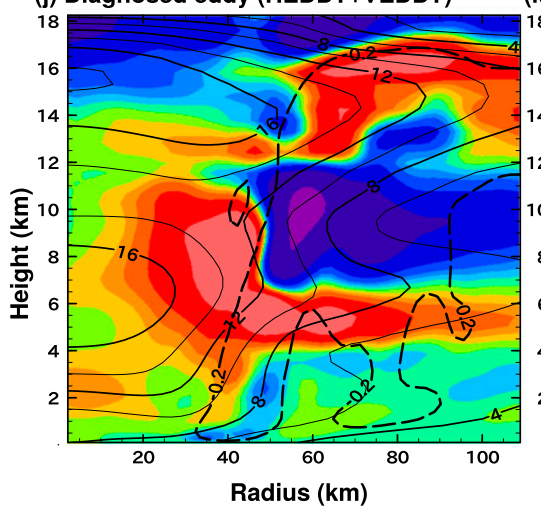

(e) Horizontal advection (HADV)

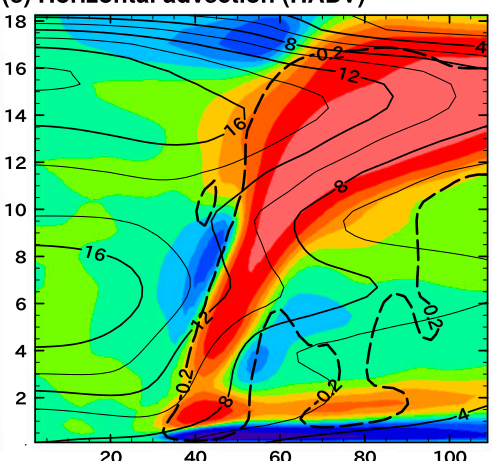

(h) Horizontal eddy (HEDDY)

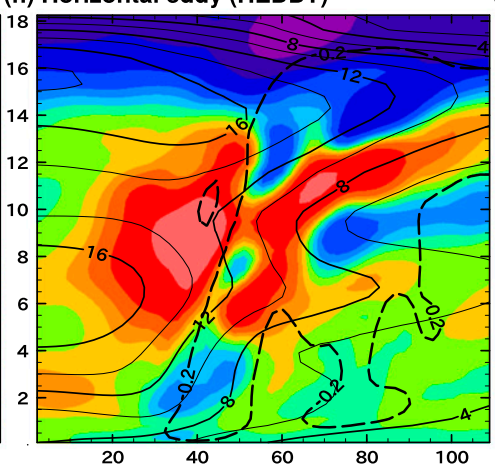

(c) Diabatic heating (DIABQ)

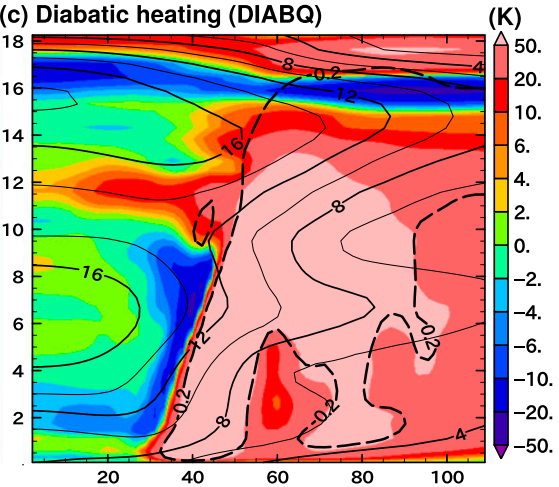

(f) Vertical advection (VADV)

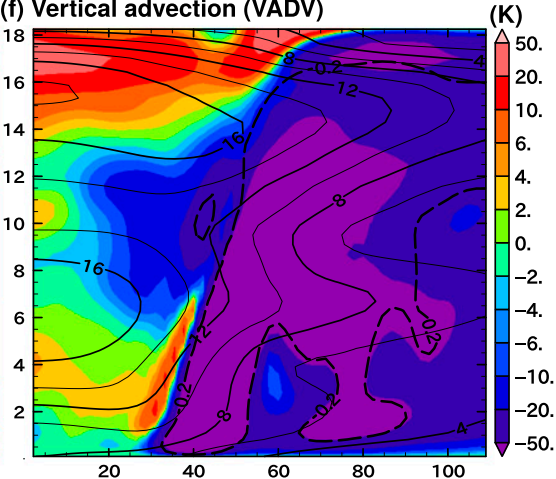

(k) Eliassen-response HADV+VADV

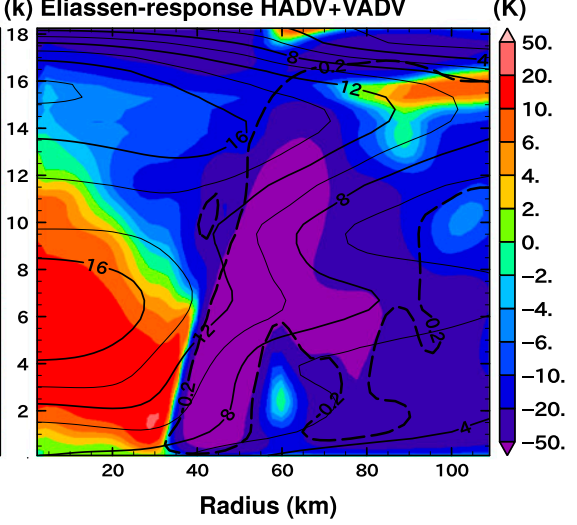

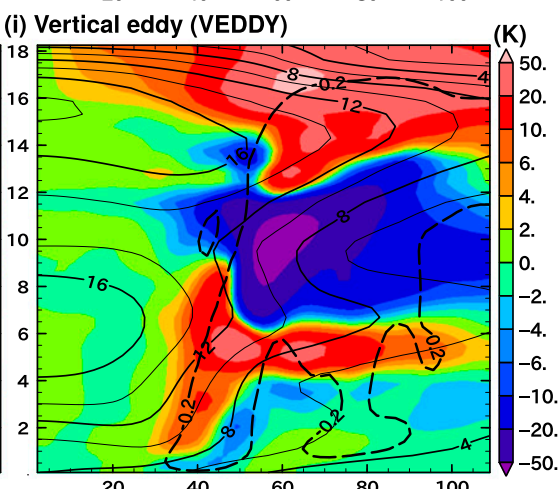

Radius (km)

FIG. 9. As in Fig. 7, but during the mature stage (0000 to 1200 UTC 21 Oct 2017). 
The lower core is also warmed in IS1, but the warming is weaker than that in the upper core. The warming is mainly controlled by VADV in the $2-4 \mathrm{~km}$ height range (Fig. 7f), HEDDY in the 5-9 $\mathrm{km}$ range (Fig. $7 \mathrm{~h}$ ), and DIABQ (mainly radiative heating) in the $8-10 \mathrm{~km}$ range (Fig. 7c). However, these positive contributions of VADV and DIABQ are mostly cancelled by negative DIABQ (mainly diffusion) and VADV in the same height ranges, respectively.

Figure 8 shows the budget analysis results for IS2. The simulated storm has a clear double warm-core structure, with a warm core in the middle troposphere (peak at 7-km height) and another in the upper troposphere (peak at $16 \mathrm{~km}$ height) as shown in Fig. 5. All levels in the storm eye are warmed (Fig. 8a). There are two warming peaks located in different layers, between 2 and $7 \mathrm{~km}$ and between 12 and $18 \mathrm{~km}$, within a radius of $40 \mathrm{~km}$. In particular, the lower level warming peak is located on the lower side of the lower core. As a result, the bottom height of the lower core rapidly descends in IS2 (Fig. 5). As in IS1 (Fig. 7f), the large warming in the upper layer is induced mainly by advection of $\bar{\theta}$ due to VADV (Fig. $8 \mathrm{f}$ ), but, as in IS1, it is partly cancelled by cooling due to HEDDY associated with strong asymmetric flows above $15-\mathrm{km}$ height (Fig. $8 \mathrm{~h}$ ), and by DIABQ due to thermal diffusion in the 16 to $18 \mathrm{~km}$ height range (Fig. 8c).

The lower-level warming, as in the upper layer, is induced mainly by VADV. The positive VADV is partly cancelled by negative DIABQ predominantly due to thermal diffusion in the $1.7-3.5 \mathrm{~km}$ layer in the eye (Fig. 8c). The descent of the lower-core bottom height in IS2 induces strong stratification at the top of the EBL $(\sim 1 \mathrm{~km})$. Thus, the simulated eye has a notable inversion layer at $1 \mathrm{~km}$ height at 0600 UTC 21 October 2017 (Fig. 3). A second warming tendency in VADV can be seen around the inner edge of the eyewall (Fig. 8f), but it is mostly cancelled by the negative DIABQ because of evaporative cooling (Fig. 8c). This feature is consistent with the idealized vortices in Stern and Zhang (2013a) and Ohno and Satoh (2015).

Figure 9 shows results of the budget analysis for MS. Although the simulated storm maintains the double warm-core structure, the large warming in the upper core that appeared in IS1 and IS2 is no longer dominant (Fig. 9a). Cooling by negative HEDDY and DIABQ is seen above $16 \mathrm{~km}$ height (Figs. 9c,h). In particular, the negative HEDDY indicates large ventilation due to vertical wind shear in the upper troposphere (Fig. 1c), as the storm is moving northward into the middle latitudes (e.g., Tang and Emanuel 2012). Note that warming due to positive VADV continues in the upper core (Fig. 9f). Therefore, because the negative tendency of HEDDY and positive tendency of VADV partly cancel each other, the upper core can mostly maintain the amplitude of the temperature anomaly. Below $14 \mathrm{~km}$ height (i.e., the lower part of the upper core), HEDDY provided positive tendency.

Large warming is still seen in the lower core (Fig. 9a). This warming is predominantly due to positive HEDDY (Fig. 9h), and positive $\mathrm{VADV}$ at a height of $4 \mathrm{~km}$ near the center (Fig. 9d). We are interested in the contribution of HEDDY at the $4 \mathrm{~km}$ height where the peak height of the actual change of potential temperature is located (Fig. 9a). Figure 10 shows $u^{\prime}$ and $\theta^{\prime}$ at $4 \mathrm{~km}$ height during MS. There is an approximate wavenumber- 1 pattern around the eye, with $\theta^{\prime}>0$, and $u^{\prime}<0$ on the northeast side and $\theta^{\prime}<0$, and $u^{\prime}>0$ on the southwest side. Thus, asymmetric radial flux of potential temperature has a negative sign and contributes to the eye warming. Stern and Zhang (2013a) also reported this pattern and suggested that it may be due to dynamical instability. In our simulation, however, higher wavenumber perturbations at small scales are superposed on the asymmetric pattern. For example, at 0300 UTC 21 October 2017, there are two peaks of negative radial flux of potential temperature $\left(\theta^{\prime}>0\right.$ and $\left.u^{\prime}<0\right)$, on the northwest and southeast sides of the eye, at a radius of around $20 \mathrm{~km}$ (Fig. 10e). The wavenumber-2 perturbations of $\theta^{\prime}$ are approximately out of phase with those of $u^{\prime}$. The perturbations with negative radial flux contribute to the eye warming.

Although the simulated vertical wind shear during MS was much stronger than that in the analysis (Fig. 1c), such perturbations were also exhibited in the observations. Tsukada and Horinouchi (2020) identified mesovortices with the wavenumber- 1 or wavenumber- 2 scales in the eye of Lan during a period of 0000 to 0600 UTC 21 October 2017, based on the Himawari-8 satellite. Figure 11 shows azimuthally averaged potential vorticity (PV) fields in the simulation. The $\mathrm{PV}$ below a height of $5 \mathrm{~km}$ had local maxima at radii of 30 to $40 \mathrm{~km}$ along isentropic surfaces during IS1, IS2, and MS. The local maxima of the PV can be generated by the eyewall convection. This feature in the PV fields satisfying a necessary condition for the barotropic instability suggests radial redistribution of high PV in the eyewall associated with asymmetric eddies. In fact, the PV below the $5 \mathrm{~km}$ height near the center increased as the storm intensifies. The PV increase can be caused by the asymmetric PV mixing as a result of the instability. The low-level eye warming by HEDDY can be associated with the asymmetric PV mixing (e.g., Hendricks and Schubert 2010; Tsujino and Kuo 2020).

The simulated storm had an asymmetric eyewall in the large vertical wind shear. The active convection in the asymmetric eyewall was located on the downshear side (Fig. 2j). Coincided with the asymmetric convection, there was large warming associated with the asymmetric subsidence (i.e., VEDDY) in the outer edge of the eye at levels of 2-8 km and above $14 \mathrm{~km}$ height (Fig. 9i). The warming is partly consistent with warm core formation due to asymmetric processes under vertical wind shear proposed by Chen and Gopalakrishnan (2015). Such small-scale perturbations might be caused by not only dynamical instability but also eyewall convection. The pattern of cooling in the upper core and warming in the lower core maintains the storm intensity in MS.

The budget analysis results clarified that the simulated double warm-core structure was warmed mainly by positive VADV during the IS1, IS2, and MS stages. Thus, the warming process associated with VADV is of interest. Ohno and Satoh (2015) suggested on the basis of their idealized simulation that the upper warm core is induced mainly by the balanced response to heating and momentum sources in the inner core. Therefore, in the present simulation, warming processes due to the balanced response were estimated in the similar way to Ohno and Satoh (2015). The diagnosed secondary circulations 
(a) 0000 UTC 21 Oct

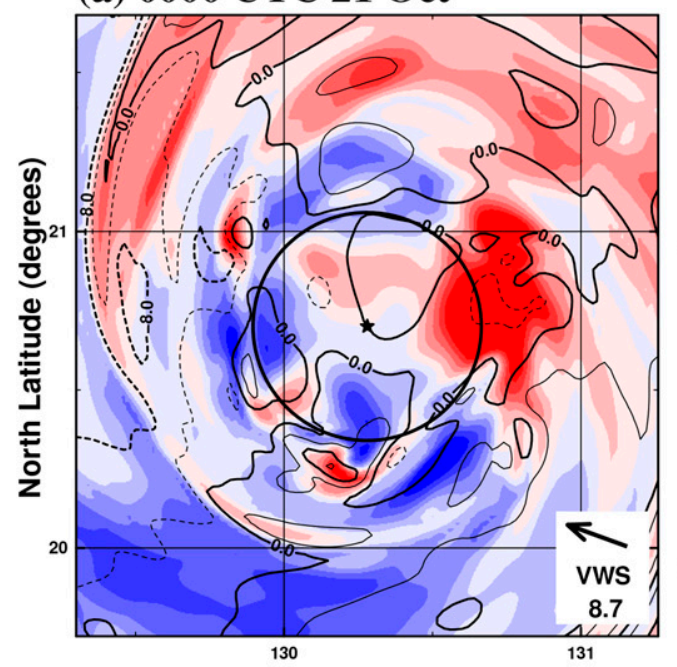

(c) 0600 UTC 21 Oct

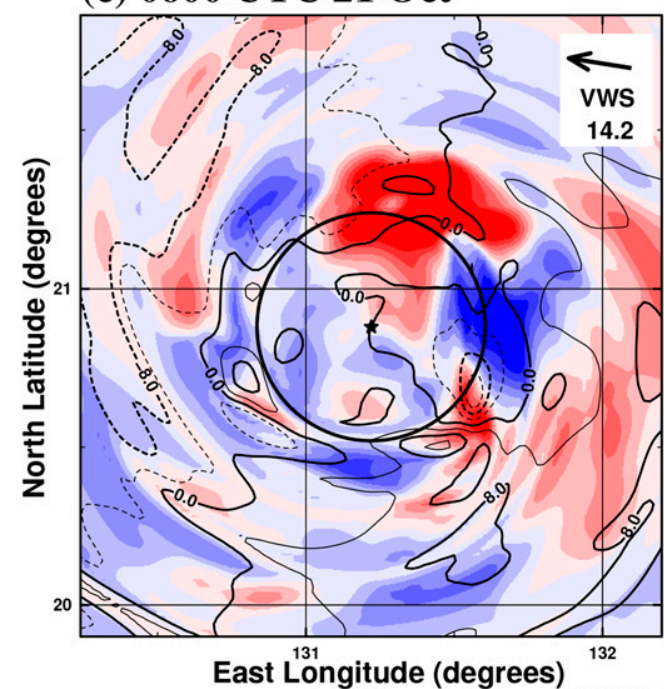

(b) 0300 UTC 21 Oct

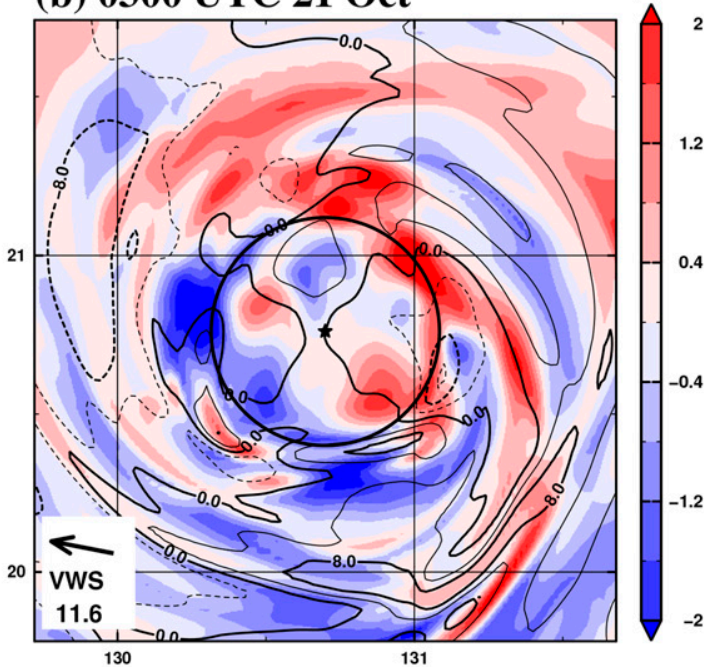

(d) 0900 UTC 21 Oct

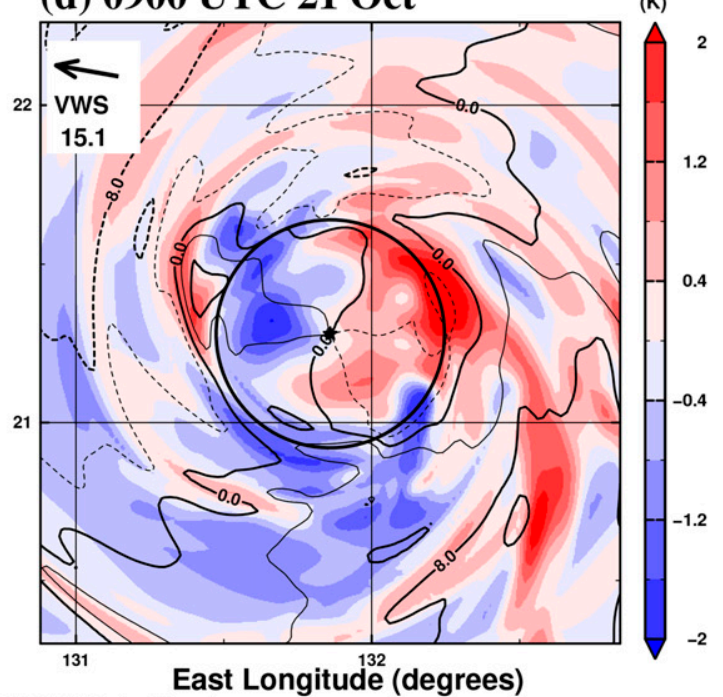

(e) $R=20 \mathrm{~km}(0300$ UTC 21 Oct)

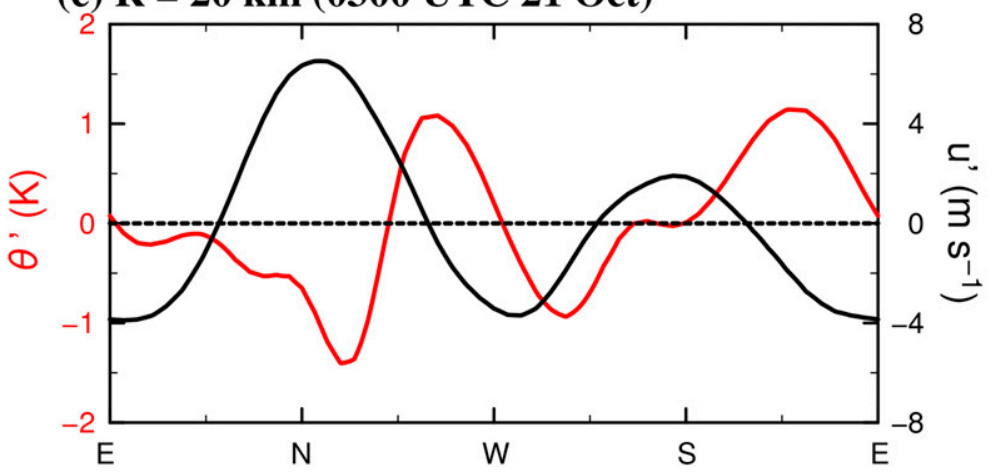

FIG. 10. Horizontal distribution of asymmetric potential temperature (color scale; K) and the storm-relative asymmetric component of radial velocity (contours; $\mathrm{m} \mathrm{s}^{-1}$ ) at $4 \mathrm{~km}$ altitude around the simulated storm at (a) 0000 , (b) 0300, (c) 0600, and (d) 0900 UTC 21 Oct 2017. Solid and dashed contours denote outflow and inflow, respectively, around the storm center (black star). The black circle indicates the $40 \mathrm{~km}$ radius from the storm center. (e) Azimuthal profiles of the asymmetric potential temperature (red line; K) and the storm-relative asymmetric component of radial velocity (black line; $\mathrm{m} \mathrm{s}^{-1}$ ) at a radius of $20 \mathrm{~km} \mathrm{in} \mathrm{(b).} \mathrm{In} \mathrm{(a)-(d),} \mathrm{the} \mathrm{vectors} \mathrm{and} \mathrm{values} \mathrm{indicate}$ directions and strength of the vertical wind shear in the simulation (corresponding to the red line in Fig. 1c). 

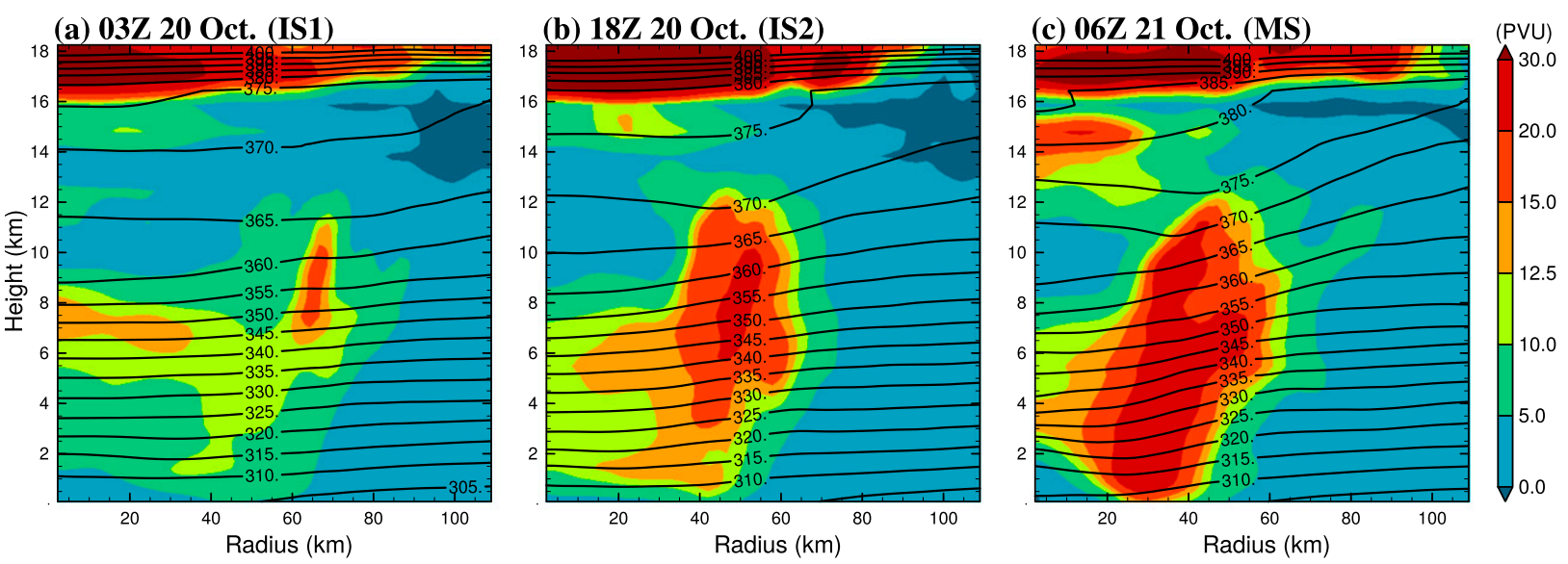

FIG. 11. Vertical cross sections of azimuthally averaged PV (color; PVU $=10^{-6} \mathrm{~K} \mathrm{~m}^{2} \mathrm{~kg}^{-1} \mathrm{~s}^{-1}$ ) and potential temperature (contour; K) around the inner core in the simulated Lan at (a) 0300 UTC 20 Oct, (b) 1800 UTC 20 Oct, and 0600 UTC 21 Oct 2017.

are driven by diabatic heating and momentum sources based on the formulation of Pendergrass and Willoughby (2009). The heating includes asymmetric eddy advection of potential temperature, microphysics, shortwave and longwave radiation, turbulent mixing, and numerical diffusion processes (i.e., HEDDY + VEDDY + DIABQ). The momentum sources include forcing due to asymmetric eddy advection of momentum, surface friction, turbulent mixing, and numerical diffusion processes. Radial and vertical flows in the balanced framework were diagnosed every $45 \mathrm{~s}$ with the heating and momentum sources in the model outputs, and averaged during each analysis period. ${ }^{5}$ To directly compare with the potential temperature budget, the axisymmetric advection of the potential temperature associated with the diagnosed flows every $45 \mathrm{~s}$ was assessed by temporal average for the $12 \mathrm{~h}$ in IS1, IS2, and MS.

Moreover, HEDDY and VEDDY were estimated by subtracting advection directly output by the model from the diagnosed HADV and VADV, respectively. The accuracy of the diagnosed HADV and VADV was therefore examined by comparing the direct output with the diagnosis based on the exact definitions in Eq. (2), as was done previously (Ohno and Satoh, 2015). The diagnosed HEDDY and VEDDY were consistent with those in the direct output during all stages (Figs. 7g, 7j, 8g, 8j, 9g, and 9j). Therefore, we consider HADV and VADV to be sufficiently accurate to discuss their axisymmetric contribution.

Total warming due to advection associated with the balanced response is shown in Figs. 7k, 8k, and 9k, corresponding to IS1, IS2, and MS, respectively. The warming pattern due to the balanced response is similar to the HADV + VADV pattern around the upper layer (above $14 \mathrm{~km}$ ) within the eye in IS1 (Figs. 7d,k). The warming due to the balanced response had

\footnotetext{
${ }^{5}$ We examined two types of the calculation: 1) the diagnoses every 45-s and average during each analysis period, and 2) the single diagnosis with average of the 45-s model outputs during each analysis period. The difference is minor (not shown).
}

positive signs around the lower layer ( 2 to $6 \mathrm{~km}$ ) within the eye in IS2 and MS (Figs. 8d,k and 9d,k), but the amplitude of the balanced warming was greater than that of the HADV + VADV pattern. In contrast to the two separate warming peaks corresponding to each warm core in the budget analysis results, the balanced response warming had a single peak in the lower core within the eye during IS2 and MS. The balanced response had no warming effect in the upper layers above 16 and $14 \mathrm{~km}$ during IS2 and MS, respectively. Upper-layer cooling due to the balanced response was also exhibited near the inner edge of the eyewall in IS1.

Figure 12 shows the axisymmetric secondary circulations in the balanced framework and model output during IS1, IS2, and MS. Outside the eye, the secondary circulations diagnosed in the balanced framework were in good agreement with those in the simulation during the three stages, except that the boundary layer inflow and upper-level outflow in the diagnosis were weaker than those in the simulation. On the other hand, the diagnosis exhibited a single peak of the subsidence inside the eye in the vertical direction during the three stages (Figs. 12d-f). The feature is different from double peaks of the eye subsidence in the simulation (Figs. 12a-c). These profiles of the vertical velocity in the diagnosis and simulation mostly corresponded with the warming in the eye. In particular, there was a large difference of the warming profile between the balanced response and simulation in the upper core during IS2 and MS, and in the middle troposphere during IS1 and IS2.

These results indicate that it is difficult to fully explain the intensification and maintenance processes of the simulated warm cores as balanced-response warming, which lacks double peaks. Alternatively, the path of the air mass penetrating the eye may provide additional information on the intensification and maintenance of the double warm-core structure.

\section{Backward trajectory}

To examine the air mass penetrating the eye, a backwardtrajectory analysis was conducted for initial times every hour from 1200 UTC 19 October to 1200 UTC 21 October 2017, 
(a) CReSS (IS1)

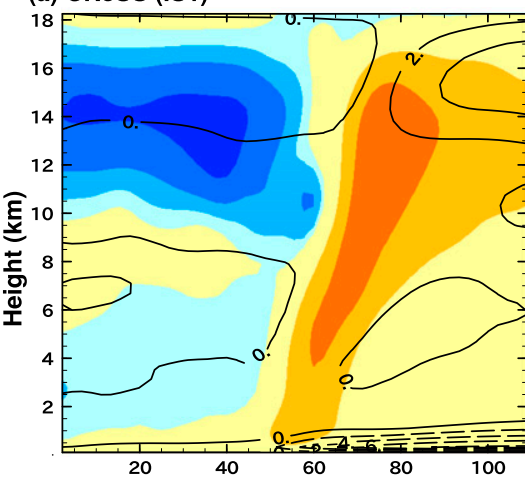

(d) Eliassen (IS1)

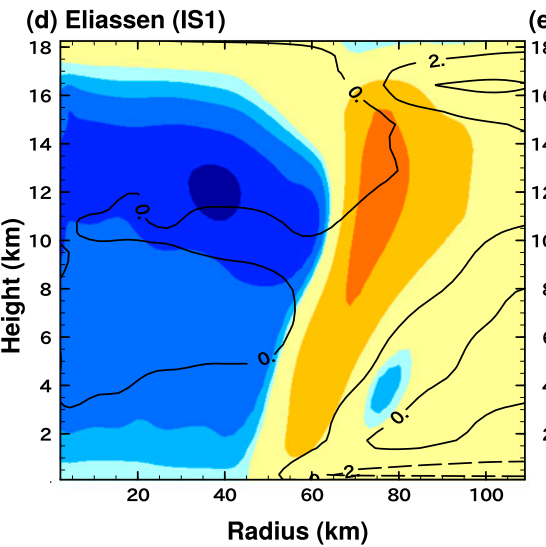

(b) CReSS (IS2)

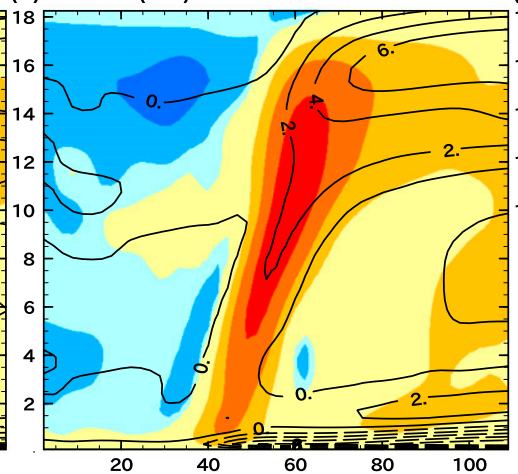

(e) Eliassen (IS2) (c) CReSS (MS)

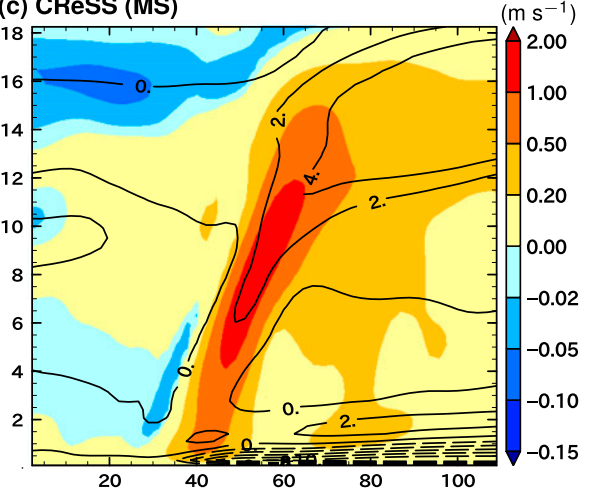

(f) Eliassen (MS)
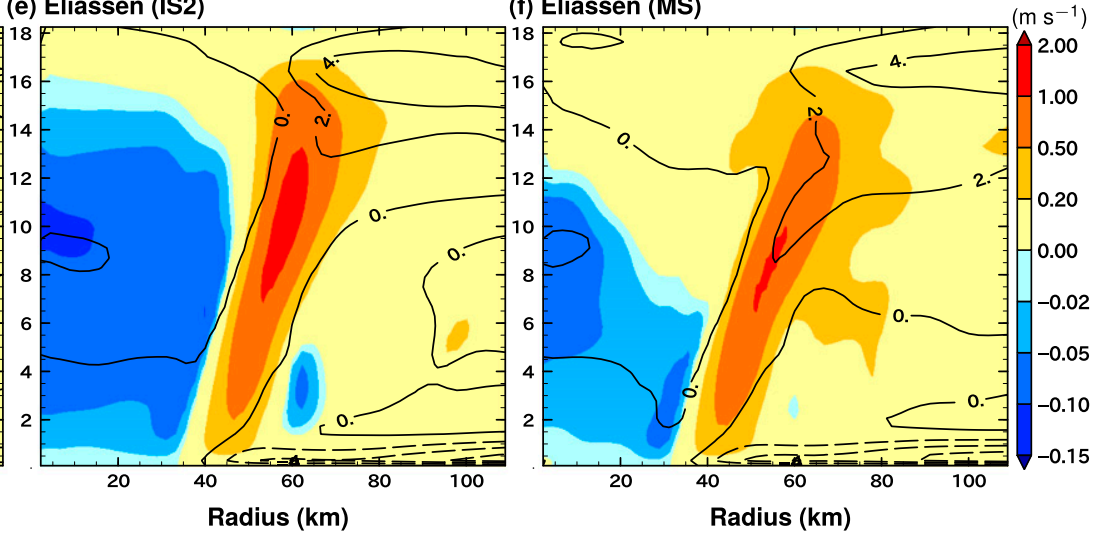

FIG. 12. Radius-height cross sections of the axisymmetric vertical (colors; $\mathrm{m} \mathrm{s}^{-1}$ ) and radial (contours; $\mathrm{m} \mathrm{s}^{-1}$ ) velocities in the (a)-(c) simulation and (d)-(f) balanced framework during (a),(d) IS1, (b),(e) IS2, and (c),(f) MS. The secondary circulations were temporally averaged over each stage with the 45 -s output.

as described in section 2c. The initial and final times of the calculation at every hour were defined as $t_{b}=0$ and $-12 \mathrm{~h}$, respectively. Figure 13 shows examples of the paths of parcels located outside each annular volume with a $35-\mathrm{km}$ radius and heights of 14.3 to $15.9 \mathrm{~km}$ and 2.1 to $3.9 \mathrm{~km}$ (i.e., upper and lower layers in section 2c) at $t_{b}=-1 \mathrm{~h}$ with the initial time of 0000 UTC 21 October 2017. Most parcels arriving at both layers in the eye ascended along the eyewall at a radius of around $50 \mathrm{~km}$ before penetrating the eye. This result is consistent with the result reported by Stern and Zhang (2013b). Most parcels reached their maximum altitude along the path before moving inward and penetrating the eye. In addition, some of the lowerand upper-layer parcels exhibited radial overshoot in the EBL (e.g., Bryan and Rotunno 2009; Rotunno and Bryan 2012).

Figure 14 shows the evolution of parcels located outside each annular volume with the $35-\mathrm{km}$ radius and heights of 14.3-15.9, 7.1-9.1, and 2.1-3.9 km (i.e., upper, middle, and lower layers in section $2 \mathrm{c}$ ) at $t_{b}=-1 \mathrm{~h}$ in the backwardtrajectory calculation from initial times (shown on the abscissa $)^{6}$ at every $1 \mathrm{~h}$ to avoid duplication in counting. The

\footnotetext{
${ }^{6}$ For example, the number of parcels at 0000 UTC 21 October 2017 in Fig. 14a is the number (normalized by all the parcels in each layer at an initial time) of the parcels located outside a $35 \mathrm{~km}$ radius at $t_{b}=-1 \mathrm{~h}$ (2300 UTC 20 October 2017).
}

parcels in Fig. 14a are associated with flows causing axisymmetric and asymmetric advection in the eye warming. In IS1, about 30\% (upper layer) and 15\% (middle layer) of all parcels were penetrating the eye from the outside, though the number fluctuated greatly with time (black and red lines in Fig. 14a). However, fewer parcels were penetrating the lower layer in the eye in the first half of IS1 (green line in Fig. 14a). In IS2, parcels penetrating the upper layer remained at about $20 \%-30 \%$ of all parcels following a decrease in the parcels in the later part of IS1. Fewer than $10 \%$ of all parcels penetrated the middle layer in IS2, but the parcels penetrating the lower layer rapidly increased for the first half of IS2. In MS, the parcels penetrating the upper layer did not drastically change from IS2, but the parcels penetrating the middle layer slightly increased, and the parcels penetrating the lower layer gradually decreased. The increase in the middle layer was associated with asymmetric flows in positive HEDDY (Figs. 9h and 10).

The maximum altitude of the upper-layer parcels extended to $18 \mathrm{~km}$, but most parcels were concentrated at an altitude of around $16 \mathrm{~km}$ (Fig. 14b). This altitude remained almost constant in MS, except for a gradual ascent to $17-\mathrm{km}$ altitude. In contrast to the concentrated upper-layer parcels, the maximum altitude of the lower-layer parcels in IS2 ranged from 2 to $8 \mathrm{~km}$ (Fig. 14c).

Of particular interest is how the parcels in the two warm cores were able to penetrate the eye. According to the budget 
(a) Upper layer

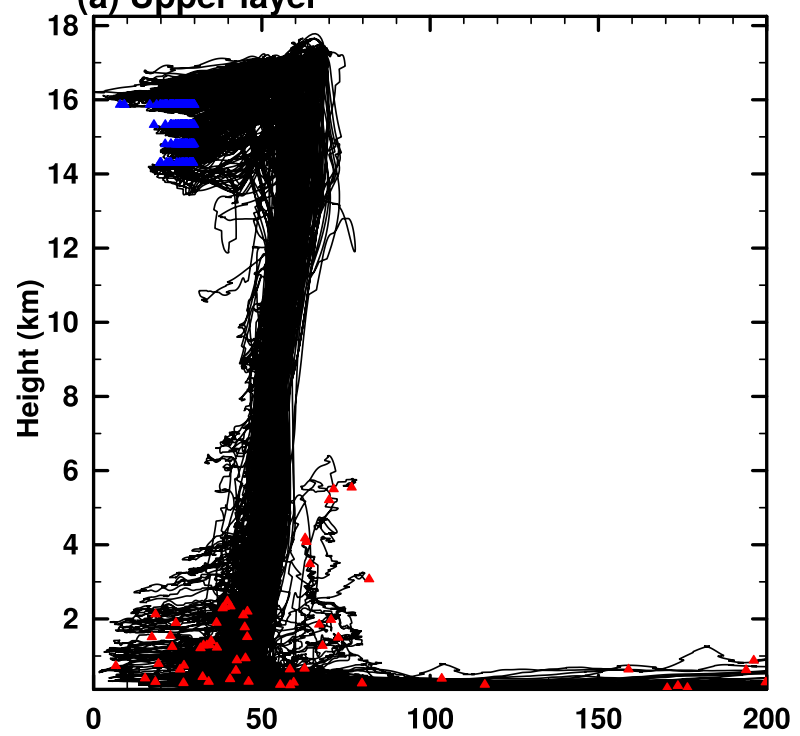

(b) Lower layer

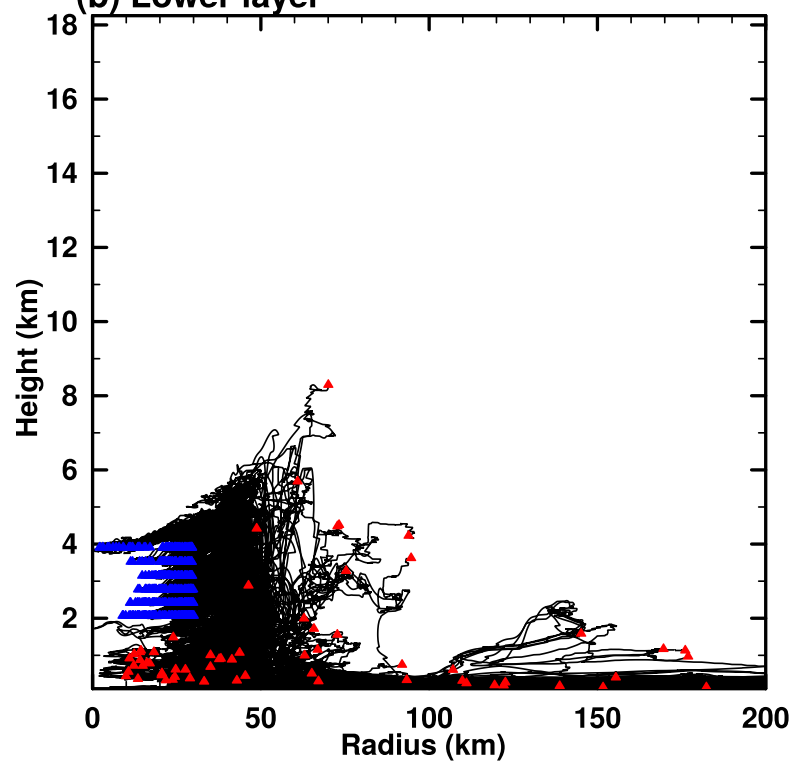

FIG. 13. Examples of paths of parcels coming within a radius of $35 \mathrm{~km}$ in the (a) upper and (b) lower layers. Only parcels located on the outside of each annular volume with a $35 \mathrm{~km}$ radius and heights of 14.3 to $15.9 \mathrm{~km}$ and 2.1 to $3.9 \mathrm{~km}$ at $1 \mathrm{~h}$ prior to each start time of the backward trajectory were counted, even though the 12-h trajectory was calculated. Blue and red triangles denote the initial $\left(t_{b}=0 \mathrm{~h}\right)$ and final $\left(t_{b}=-12 \mathrm{~h}\right)$ locations of each parcel, respectively. The initial time of the trajectory in the examples was 0000 UTC 21 Oct 2017.

and balanced response analyses, the parcels were associated with axisymmetric flows exhibiting slight differences from a balanced framework. From the perspective of axisymmetric dynamics, we hypothesize that the parcels might be accelerated inward by unbalanced processes around the maximum altitude of each parcel. Thus, the agradient wind can be useful for measuring the departure from a balanced state.
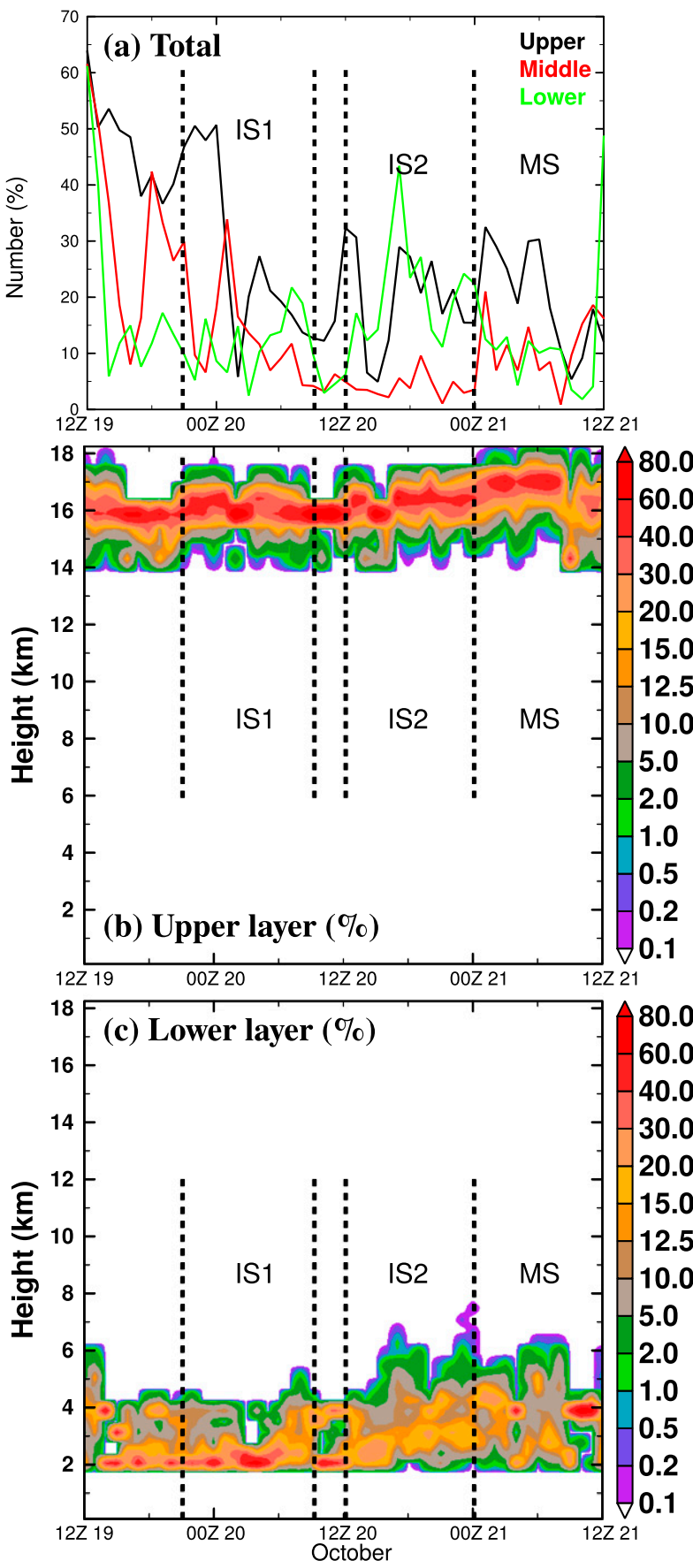

FIG. 14. Time series of (a) the total number (\%) of parcels coming within a radius of $35 \mathrm{~km}$ in each layer, and the frequencies (\%) of the maximum altitudes of the parcels penetrating into the (b) upper and (c) lower layers. The total numbers in (a) are normalized by the total number of parcels at each initial time in each layer. To avoid duplication in counting, only parcels located on the outside of the annular region in each layer at $1 \mathrm{~h}$ prior to each start time of the backward trajectory were counted, even though the 12-h trajectory was calculated. 
(a) 0224 UTC 20 (IS1)

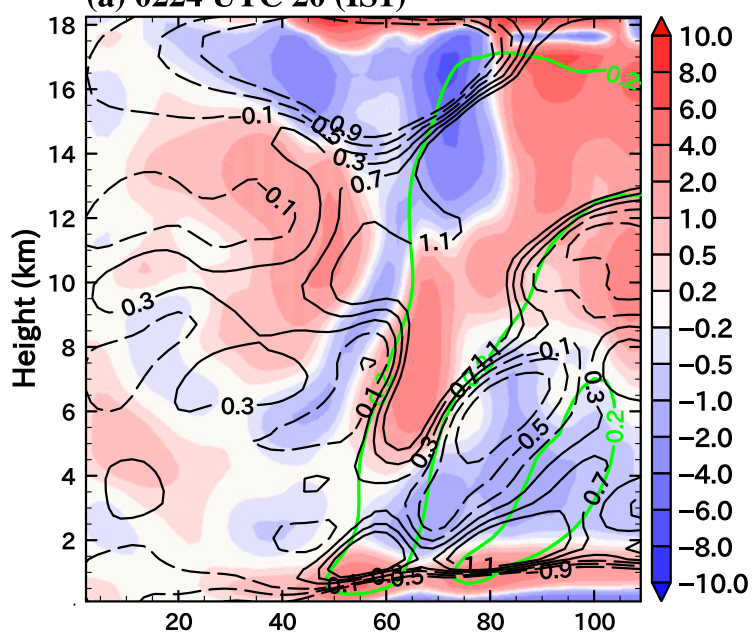

(b) 2012 UTC 20 (IS2)

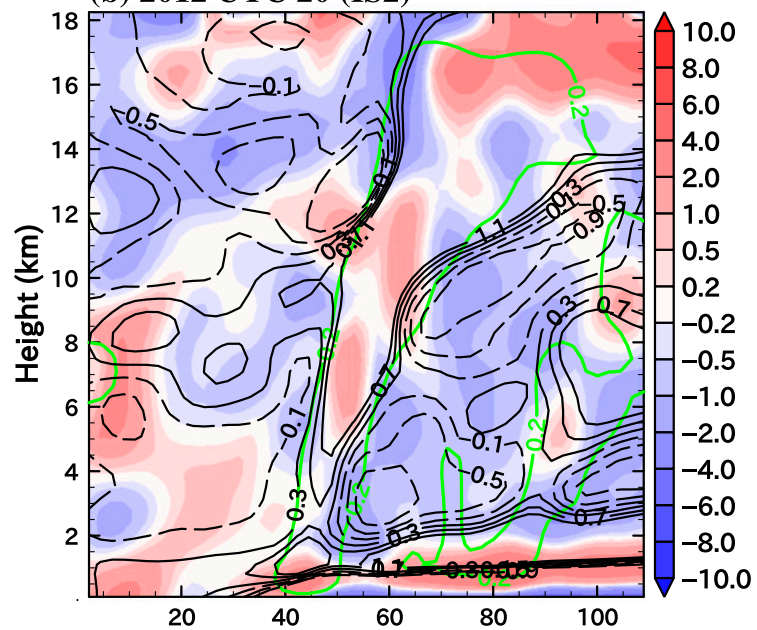

(c) 0521 UTC 21 (MS)

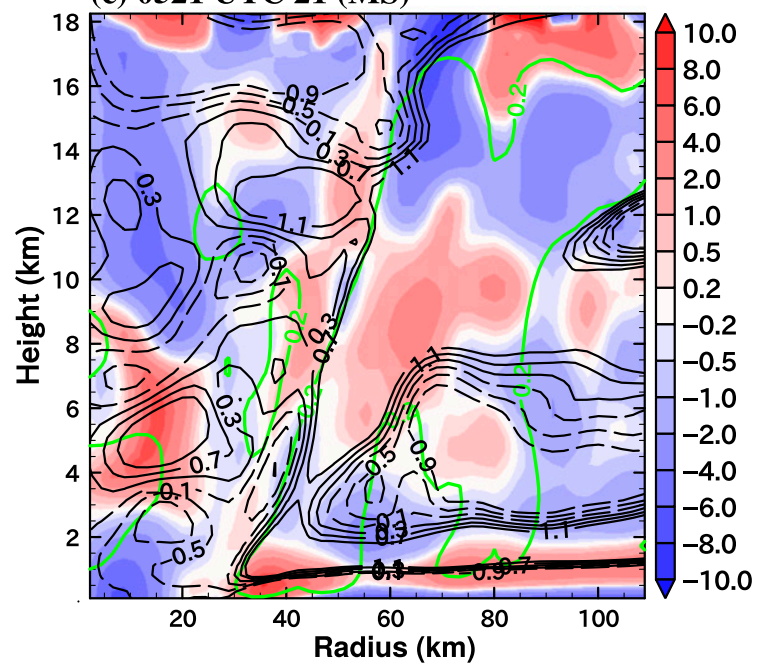

FIG. 15. Radius-height cross sections of agradient wind (color scale; $\mathrm{m} \mathrm{s}^{-1}$ ), radial flow from -0.9 to $1.1 \mathrm{~m} \mathrm{~s}^{-1}$ (black contours; interval of $0.2 \mathrm{~m} \mathrm{~s}^{-1}$ ), and updrafts of $0.2 \mathrm{~m} \mathrm{~s}^{-1}$ (green solid contours) at (a) 0224 UTC 20 Oct (IS1), (b) 2012 UTC 20 Oct (IS2), and (c) 0521 UTC 21 Oct 2017 (MS). Red and blue colors indicate super- and subgradient winds, respectively.

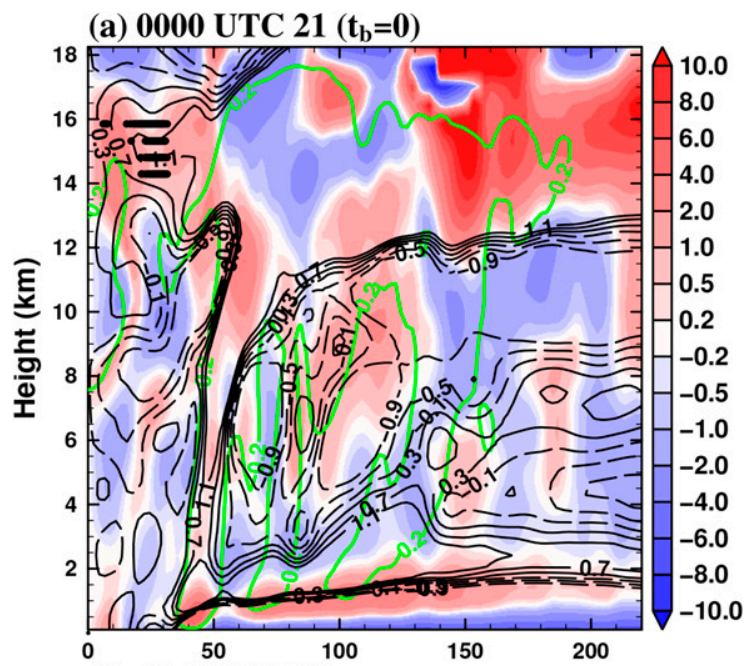

(b) 2244 UTC 20

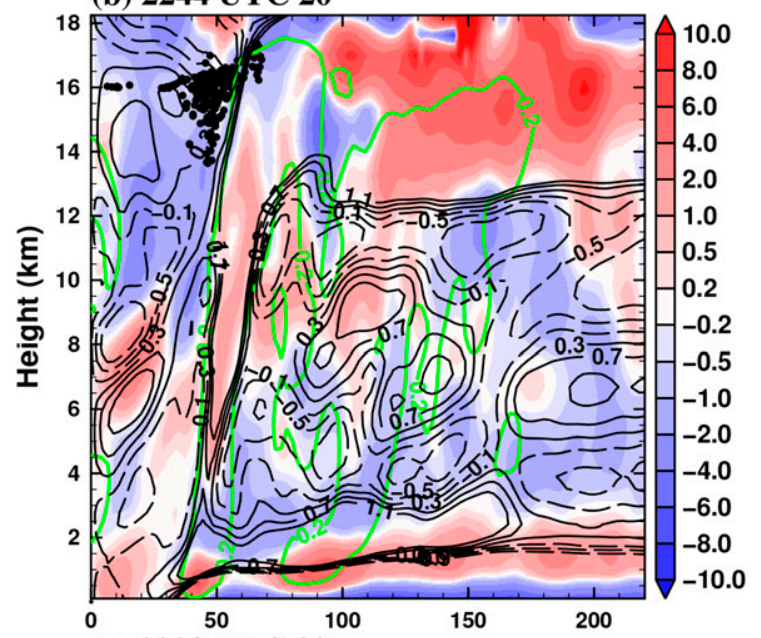

(c) 2228 UTC 20

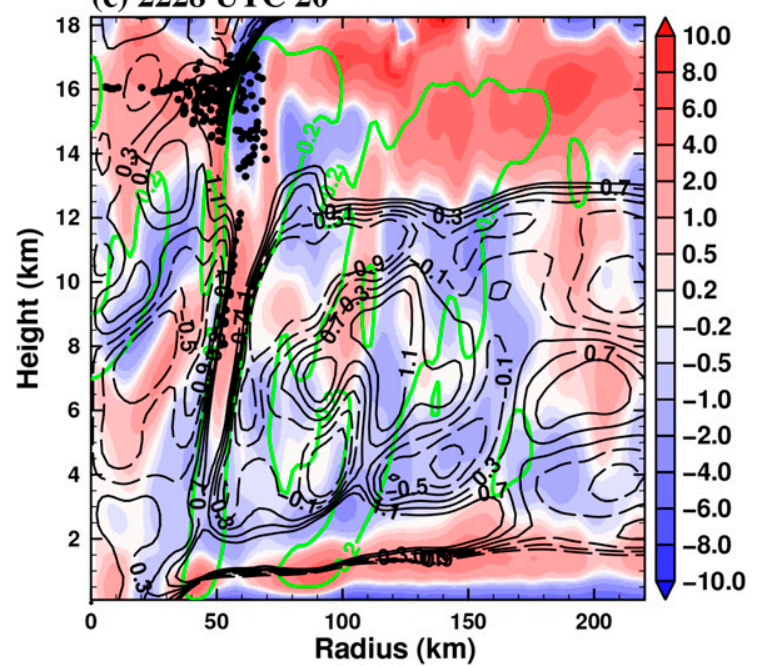

FIG. 16. Radius-height cross sections of agradient wind (color scale; $\mathrm{m} \mathrm{s}^{-1}$ ), radial flow from -0.9 to $1.1 \mathrm{~m} \mathrm{~s}^{-1}$ (black contours; interval of 0.2 $\mathrm{m} \mathrm{s}^{-1}$ ), and updrafts of $0.2 \mathrm{~m} \mathrm{~s}^{-1}$ (green solid contours) at (a) 0000 UTC 21 Oct, (b) 2244 UTC 20 Oct, and (c) 2228 UTC 20 Oct 2017. Black dots in each panel indicate the penetrating parcels into the upper core with the initial time $\left(t_{b}=0\right)$ of 0000 UTC 21 Oct 2017, which is shown in Fig. 13a, at each time. 

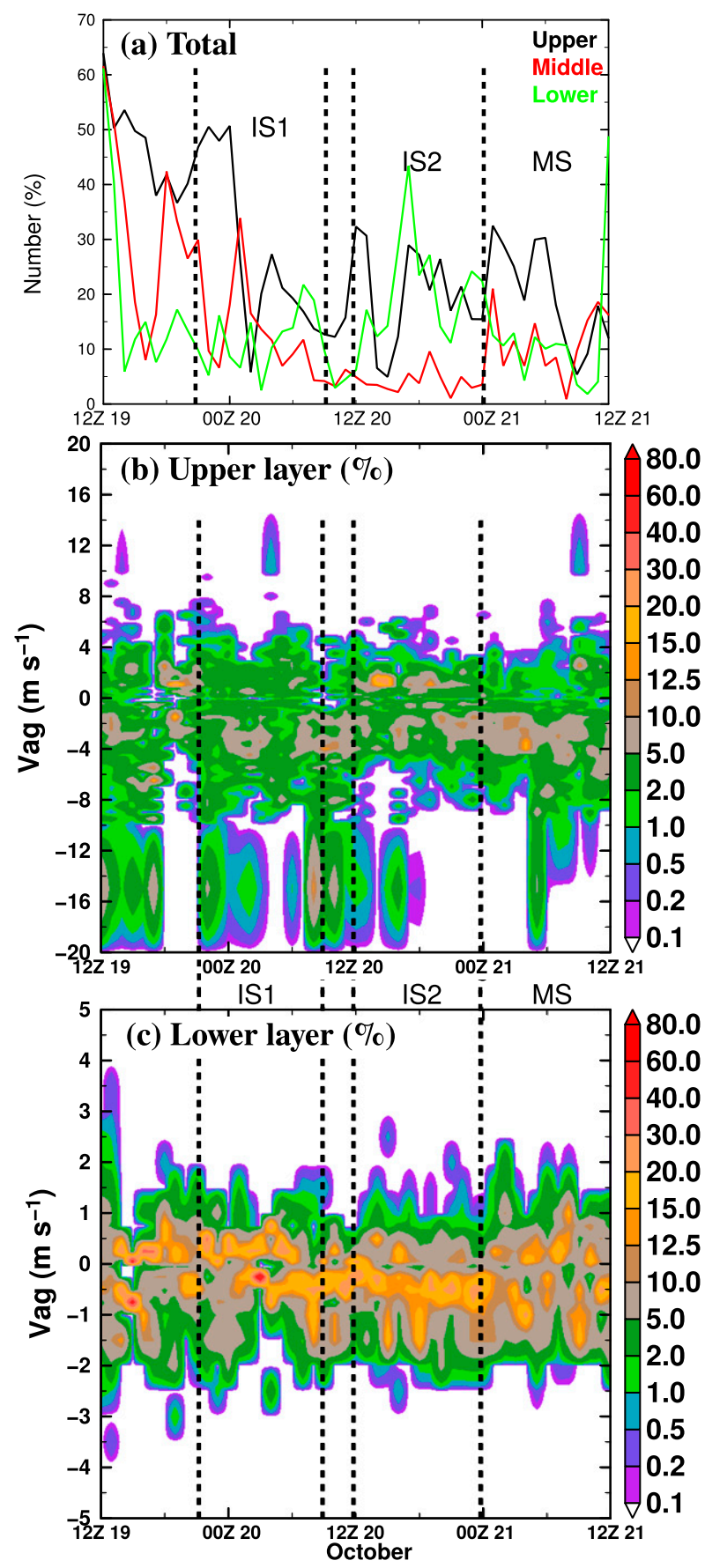

FIG. 17. As in Fig. 14, but for frequencies (\%) of agradient wind at the maximum altitude of the parcels penetrating into the (b) upper and (c) lower layers. The parcels were counted by the same way in Figs. 14b and 14c.

Figure 15 shows snapshots of the agradient wind. During all stages, the wind was subgradient on the inner side of the eyewall and exceeded $2 \mathrm{~m} \mathrm{~s}^{-1}$ at heights of 12 to $18 \mathrm{~km}$, corresponding to the maximum altitude of the upper-layer parcels. Clear inflows, partly collocated with the subgradient region, were dominant in the eye. There was another subgradient wind peak (but relatively weak at up to $2 \mathrm{~m} \mathrm{~s}^{-1}$ ) in the $2-5 \mathrm{~km}$ layer of the eyewall, corresponding to the maximum altitude of the lowerlayer parcels. Moreover, there were supergradient winds, exceeding $2 \mathrm{~m} \mathrm{~s}^{-1}$, at 5 to $12 \mathrm{~km}$ in the eyewall during all stages. Note that the agradient wind speed showed large fluctuations with time. Figure 16 shows an example of the fluctuations of the agradient wind associated with the parcels penetrating the upper layer. The parcels with the initial time of 0000 UTC 21 October 2017 in the trajectory calculation (corresponding to Fig. 13a) were located within the $35 \mathrm{~km}$ radius at the initial time (Fig. 16a). Some of the parcels were associated with an area with subgradient wind at around levels of 14 to $17 \mathrm{~km}$ in the inner edge of the eyewall updraft during a period of 2200 to 2300 UTC 20 October 2017 (Figs. 16b,c and Movie 1). We caution that axisymmetric radial flows are small in the upper warm core. Radial movement of the parcels in the eye can be associated with not only axisymmetric but also asymmetric radial flows, consistent with large HEDDY in the upper core (Fig. 8e). On the other hand, the upper-core warming is mainly due to the VADV in Fig. 8f. Descending motions of the parcels in the upper core can be mainly due to the axisymmetric subsidence.

Figure 17 shows frequencies of agradient wind at maximum altitude of each parcel penetrating the lower and upper layers. The upper-layer parcels at the maximum altitude were dominated by subgradient winds in the range of 1 to $4 \mathrm{~m} \mathrm{~s}^{-1}$. Thus, the parcels at around the maximum height in the upper layers were accelerating inward. The lower-layer parcels were dominated by subgradient winds of $2 \mathrm{~m} \mathrm{~s}^{-1}$ or less. The subgradient wind speeds in the lower-layer parcels were much lower than those in the upper-layer parcels. This result suggests that the lower-layer warming can be partly attributed to the balanced response, consistent with the qualitative similarity between total advection and advection due to the balanced response. The fact that fewer parcels penetrated the middle layer may reflect the supergradient wind at heights of 5 to $12 \mathrm{~km}$ in the eyewall, which suggests that most parcels there were accelerating outward. ${ }^{7}$

These results suggest that the inconsistencies in upper core warming between the budget and the balanced response during IS2 and MS are attributable to agradient winds (i.e., unbalanced processes) around the simulated eyewall. Moreover, the inconsistency during MS may be due to strongly asymmetric warming (i.e., HEDDY) in addition to agradient winds. The agradient wind in the eyewall might be associated with eyewall convection, because it fluctuated greatly with time. The dynamical mechanism responsible for the formation of the agradient wind remains unresolved and needs to be investigated in the future.

\section{Summary and conclusions}

Full understanding of a TC's warm-core structure and its evolution is important for understanding of TC intensification

\footnotetext{
${ }^{7}$ Due to insufficient number of parcels penetrating the middle layer in IS2 (Fig. 14a), it is difficult to estimate the frequency of agradient wind for the parcels in the middle layer.
} 

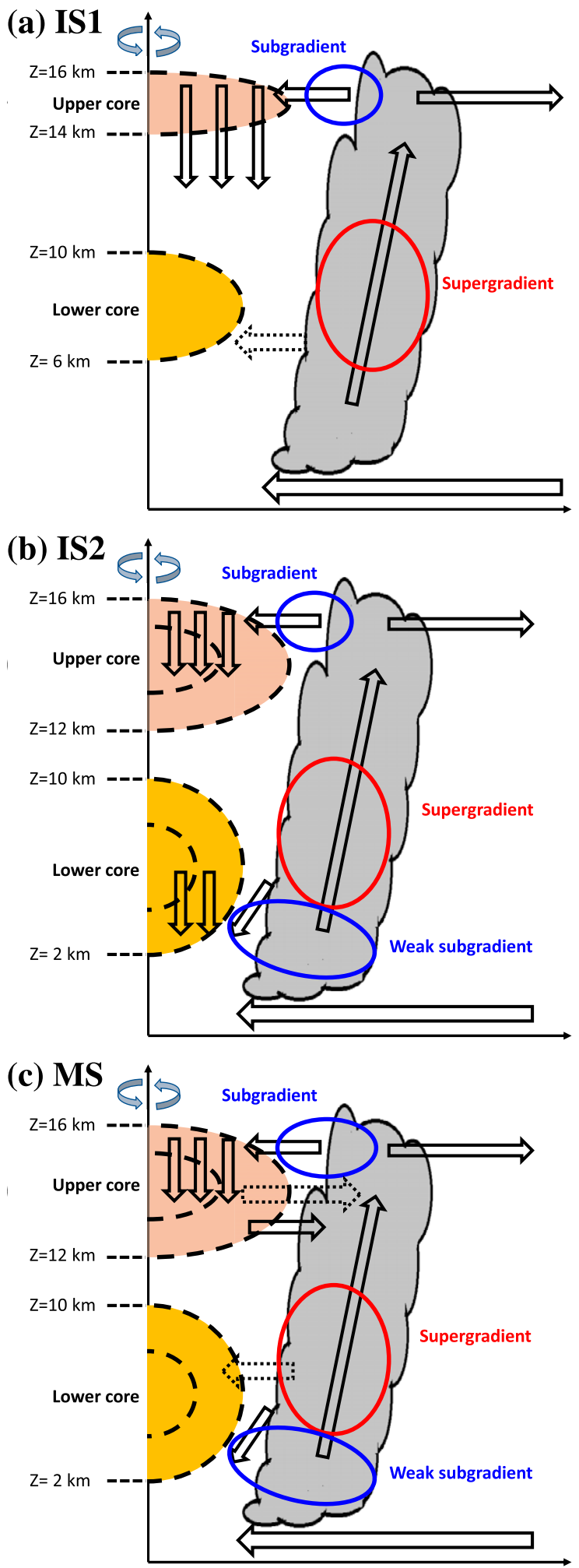

FIG. 18. Conceptual diagram of intensification and maintenance of the double warm-core structure during (a) IS1, (b) IS2, and (c) MS in the present study. The gray region corresponds to the eyewall cloud in the simulation. Solid-line arrows indicate axisymmetric flows, and dotted-line arrows indicate asymmetric potential dynamics. During a special in situ observation campaign of a typhoon's inner core (T-PARCII) in 2017, an aircraft entered the eye of the intense Typhoon Lan, and dynamic and thermodynamic fields around the storm's inner core were observed by dropsonde. The observations indicated that the typhoon had a clear double warm-core structure during its mature stage.

A numerical simulation was performed with a cloud-resolving model to examine the warming processes of the storm's two warm cores. The simulation reasonably captured the storm track, intensity, and inner-core structure. In particular, its intensity and intensification rate during 19-20 October 2017 were consistent with the best track estimations. The simulation during the most rapidly intensifying stage was reasonable for our analysis. We caution that the simulation did not capture persistent convection near the center before the most rapidly intensifying stage, and the storm exhibited an asymmetric eyewall caused by the overestimation in the simulated vertical shear during the mature stage. However, the simulation results before the most rapidly intensifying stage and during the mature stage were still helpful for comparison with the inner-core evolution during the most rapidly intensifying stage.

Moreover, the temperature profile of the simulated eye was comparable to that in the T-PARCII dropsonde observations (Fig. 3). The simulated thermal structure in the eye was characterized by clear double warm-core structure with a lower peak at $6 \mathrm{~km}$ height and an upper peak at $16 \mathrm{~km}$.

The simulation showed that two clear warming peaks formed before 0000 UTC 19 October 2017 (Fig. 5). After the formation of the double warm-core structure, further intense warming of both cores occurred, and the bottom height of each core rapidly descended. This amplification of the double warmcore structure coincided with the deepening of the central pressure during the most rapidly intensifying stage of the storm.

A potential temperature budget analysis and a backward trajectory analysis were conducted to examine the warming processes in the two warm cores during the early and later stages of the most rapidly intensifying period (IS1 and IS2) and the maintenance stage (MS) of the storm. Figure 18 shows schematically the evolution of the double warm-core structure as inferred from the analysis results.

Warming in the upper core was adiabatic (VADV), and it was accompanied by strong axisymmetric subsidence in the IS1, IS2, and MS stages. This warming in the upper core is the major contributor to storm intensification (downward open vectors in Fig. 18). The air mass entering the upper core region originated at a low level and passed through the eyewall. Then, the air mass in the subgradient region on the inner side of the eyewall was accelerated inward (upper-level blue-line ellipse in Fig. 18). On the other hand, negative tendencies of potential

temperature advection. Red- and orange-shaded half ellipses denote upper and lower warm cores, respectively. The dashed black contours show the approximate positive temperature anomaly (i.e., outlines of the warm cores). Open ellipses drawn with blue and red lines indicate sub- and supergradient regions, respectively. See the main text for details. 
TABLE 4. Summary of the datasets used in the present study.

\begin{tabular}{lll}
\hline \multicolumn{1}{c}{ Dataset } & \multicolumn{1}{c}{ Authorization } & \multicolumn{1}{c}{ Accessibility } \\
\hline Best track data & JMA & JTWC \\
CReSS model & Nagoya University & $\begin{array}{l}\text { www.jma.go.jp/jma/jma-eng/jma-center/rsmc-hp-pub-eg/besttrack.html } \\
\text { www.metoc.navy.mil/jtwc/jtwc.html?best-tracks } \\
\text { http://www.rain.hyarc.nagoya-u.ac.jp/ } \sim \text { tsuboki/cress_html/ } \\
\text { index_cress_eng.html (email registration is required) } \\
\text { http://precip.hyarc.nagoya-u.ac.jp/sdsu/sdsu-main.html (email registra- } \\
\text { tion is required) }\end{array}$ \\
SDSU & Nagoya University & http://www.jmbsc.or.jp/en/meteo-data.html (payment is required) \\
Global analysis & JMA & https://jra.kishou.go.jp/comm/application_en.html \\
JRA-55 & JMA & www.nrlmry.navy.mil/TC.html \\
Microwave images & Naval Research Laboratory & http://tropic.ssec.wisc.edu/real-time/amsu/ \\
AMSU images & University of Wisconsin-Madison & http://data.remss.com/SST/daily/ \\
MW_IR OI SST & Remote Sensing Systems & https://dds.cr.usgs.gov/srtm/version2_1/SRTM30/ \\
SRTM30 & USGS & Available upon request (tsuboki@nagoya-u.jp) \\
T-PARCII dropsonde & Nagoya University &
\end{tabular}

temperature from horizontal advection due to asymmetric flows (HEDDY) completely overcame the positive VADV in MS. Negative HEDDY, which is induced by environmental wind shear [i.e., the warm-core ventilation described by Tang and Emanuel (2012)], is related to the northward movement of the storm into the middle latitudes.

The lower core in IS1 intensified by the HEDDY (Fig. 18a). The HEDDY can be associated with radial redistribution of high PV from the eyewall to the eye due to dynamical instability (e.g., Hendricks and Schubert 2010; Tsujino and Kuo 2020). As in the upper core, the lower core (orange-shaded region in Fig. 18b) intensified by large VADV in IS2 (downward open vectors in Fig. 18b). The air mass was accelerated inward in the subgradient region on the inner side of the eyewall (lower-level blue-line ellipse in Fig. 18b), but the subgradient wind velocities in the lower layer were smaller than those in the upper layer. Thus, the lower-core warming may reflect both unbalanced (agradient) and balanced (gradient) dynamics. On the other hand, positive HEDDY warmed the lower core in MS. The low-wavenumber patterns of the asymmetric radial flow and potential temperature suggest that the warming is due to dynamical instabilities, as pointed out by Stern and Zhang (2013a). The mature intensity in MS was caused by the combination of lower-core warming and uppercore cooling in the simulated Lan.

The analysis results raise an interesting topic. The large warming due to VADV in the two warm cores is consistent with previous studies (e.g., Stern and Zhang 2013a; Ohno and Satoh 2015). On the other hand, the large warming in the present study is different from the warming diagnosed by the balanced response. We concluded that the unbalanced processes in the eyewall can be one possibility for an inconsistency of eye warming between the budget analysis result and the balanced response in the simulated Lan, which was induced by inward (outward) acceleration of each parcel in the strong subgradient (supergradient) region in the upper and lower (middle) layers of the eyewall (blue-line and red-line ellipses in Fig. 18).

The present simulation is only one case, however. In particular, the unbalanced processes might be highly influenced by the model physics (e.g., Rotunno and Bryan 2012). Using numerical simulations and in situ observations in combination is important for full understanding of warming processes in the eye. Therefore, additional in situ observations targeting the inner cores of typhoons, such as those obtained during the T-PARCII campaign, are needed especially in the western North Pacific, where fewer observations are available.

Acknowledgments. The fast Fourier transform computer program used for the spectral nudging is from the Fortran Library for Scientific Computing (ISPACK; http://www.gfddennou.org/library/ispack/) of Prof. Keiichi Ishioka. ST and KT thank Dr. Mayumi K. Yoshioka and Mr. Koichi Hasegawa for importing the RRTM-G package into CReSS. Authors thank the editor Dr. Christopher Rozoff and three anonymous reviewers for important and constructive comments. ST thanks Dr. Tomoki Ohno for validation of the asymmetric contribution in the budget analysis. This work was supported by Japan Society for the Promotion of Science (KAKENHI) Grants JP16H06311 and JP19H00705, and by the Ministry of Science and Technology (MOST) of Taiwan under Grants MOST-1082119-M-002-022 and MOST-107-2628-M-002-016. The numerical simulation was performed with the Earth Simulator at JAMSTEC. This study used the Dennou Common Library for drawing (http://www.gfd-dennou.org/library/dcl/) and the STPK library (http://www.gfd-dennou.org/library/davis/stpk/ index.htm.en) for numerical analyses.

Data availability statement. Information on all the data used in the present study are summarized in Table 4.

\section{REFERENCES}

Akter, N., and K. Tsuboki, 2012: Numerical simulation of Cyclone Sidr using a cloud-resolving model: Characteristics and formation process of an outer rainband. Mon. Wea. Rev., 140, 789-810, https://doi.org/10.1175/2011MWR3643.1.

Braun, S. A. 2002: A cloud-resolving simulation of Hurricane Bob (1991): Storm structure and eyewall buoyancy. Mon. Wea. Rev., 130, 1573-1592, https://doi.org/10.1175/1520-0493(2002) 130<1573:ACRSOH >2.0.CO;2.

Bryan, G. H., and R. Rotunno, 2009: Evaluation of an analytical model for the maximum intensity of tropical cyclones. 
J. Atmos. Sci., 66, 3042-3060, https://doi.org/10.1175/ 2009JAS3038.1.

Cecil, D. J., and E. J. Zipser, 1999: Relationships between tropical cyclone intensity and satellite-based indicators of inner core convection: $85-\mathrm{GHz}$ ice-scattering signature and lightning. Mon. Wea. Rev., 127, 103-123, https://doi.org/10.1175/1520-0493(1999) 127<0103:RBTCIA $>2.0$. CO;2.

Cha, D.-H., C.-S. Jin, D.-K. Lee, and Y.-H. Kuo, 2011: Impact of intermittent spectral nudging on regional climate simulation using Weather Research and Forecasting Model. J. Geophys. Res., 116, D10103, https://doi.org/10.1029/2010JD015069.

Chen, H., and D.-L. Zhang, 2013: On the rapid intensification of Hurricane Wilma (2005). Part II: Convective bursts and the upper-level warm core. J. Atmos. Sci., 70, 146-162, https:// doi.org/10.1175/JAS-D-12-062.1.

—_, and S. G. Gopalakrishnan, 2015: A study on the asymmetric rapid intensification of Hurricane Earl (2010) using the HWRF system. J. Atmos. Sci., 72, 531-550, https://doi.org/ 10.1175/JAS-D-14-0097.1.

Choi, S.-J., and D.-K. Lee, 2016: Impact of spectral nudging on the downscaling of tropical cyclones in regional climate simulations. Adv. Atmos. Sci., 33, 730-742, https://doi.org/10.1007/ s00376-016-5061-y.

D'Asaro, E. A., and Coauthors, 2014: Impact of typhoons on the ocean in the Pacific. Bull. Amer. Meteor. Soc., 95, 1405-1418, https://doi.org/10.1175/BAMS-D-12-00104.1.

Deardorff, J. W., 1980: Stratocumulus-capped mixed layers derived from a three-dimensional model. Bound.-Layer Meteor., 18, 495-527, https://doi.org/10.1007/BF00119502.

Ebert, E. E., and J. A. Curry, 1992: A parameterization of ice cloud optical properties for climate models. J. Geophys. Res., 97, 3831-3836, https://doi.org/10.1029/91JD02472.

Emanuel, K. A., 1986: An air-sea interaction theory for tropical cyclones. Part I: Steady-state maintenance. J. Atmos. Sci., 43, 585-605, https://doi.org/10.1175/1520-0469(1986)043<0585: AASITF $>2.0 . \mathrm{CO} ; 2$.

Gentemann, C. L., C. J. Donlon, A. Stuart-Menteth, and F. J. Wentz, 2003: Diurnal signals in satellite sea surface temperature measurements. Geophys. Res. Lett., 30, 1140, https:// doi.org/10.1029/2002GL016291.

—, F. J. Wentz, C. A. Mears, and D. K. Smith, 2004: In situ validation of Tropical Rainfall Measuring Mission microwave sea surface temperatures. J. Geophys. Res., 109, C04021, https://doi.org/10.1029/2003JC002092.

_- T. Teissner, and F. J. Wentz, 2010: Accuracy of satellite sea surface temperatures at 7 and $11 \mathrm{GHz}$. IEEE Trans. Geosci. Remote Sens., 48, 1009-1018, https://doi.org/10.1109/ TGRS.2009.2030322.

Hendricks, E. A., and W. H. Schubert, 2010: Adiabatic rearrangement of hollow PV towers. J. Adv. Model. Earth Syst., 2, 1-19, https://doi.org/10.3894/JAMES.2010.2.8.

Holland, G. J., 1997: The maximum potential intensity of tropical cyclones. J. Atmos. Sci., 54, 2519-2541, https://doi.org/10.1175/ 1520-0469(1997)054<2519:TMPIOT>2.0.CO;2.

Iacono, M. J., J. S. Delamere, E. J. Mlawer, and S. A. Clough, 2003: Evaluation of upper tropospheric water vapor in the NCAR Community Climate Model (CCM3) using modeled and observed HIRS radiances. J. Geophys. Res., 108, 4037, https:// doi.org/10.1029/2002JD002539.

Ito, K., and Coauthors, 2018: Analysis and forecast using dropsonde data from the inner-core region of tropical Cyclone Lan (2017) obtained during the first aircraft missions of T-PARCII. SOLA, 14, 105-110, https://doi.org/10.2151/sola.2018-018.
JMA, 2017: Joint WMO technical progress report on the global data processing and forecasting system and numerical weather prediction research activities for 2017. Japan Meteorological Agency Tech. Rep., 62 pp., https://www.jma.go.jp/jma/jma-eng/ jma-center/nwp/report/2017_Japan.pdf.

Kieu, C., V. Tallapragada, D.-L. Zhang, and Z. Moon, 2016: On the development of double warm-core structures in intense tropical cyclones. J. Atmos. Sci., 73, 4487-4506, https:// doi.org/10.1175/JAS-D-16-0015.1.

Klemp, J. B., and R. B. Wilhelmson, 1978: The simulation of threedimensional convective storm dynamics. J. Atmos. Sci., 35, 1070-1096, https://doi.org/10.1175/1520-0469(1978)035<1070: TSOTDC $>2.0 . \mathrm{CO} ; 2$.

Kobayashi, S., and Coauthors, 2015: The JRA-55 Reanalysis: General specifications and basic characteristics. J. Meteor. Soc. Japan, 93, 5-48, https://doi.org/10.2151/jmsj.2015-001.

Kondo, J., 1975: Air-sea bulk transfer coefficients in diabatic conditions. Bound.-Layer Meteor., 9, 91-112, https://doi.org/ 10.1007/BF00232256.

Lin, Y.-L., R. D. Farley, and H. D. Orville, 1983: Bulk parameterization of the snow field in a cloud model. J. Climate Appl. Meteor., 22, 1065-1092, https://doi.org/10.1175/1520-0450(1983) $022<1065$ :BPOTSF $>2.0$. CO 2 .

Louis, J. F., M. Tiedtke, and J. F. Geleyn, 1981: A short history of the operational PBL parameterization at ECMWF. Proc. ECMWF Workshop on Planetary Boundary Layer Parameterization, Reading, United Kingdom, ECMWF, 59-79, https://www. ecmwf.int/node/10845.

Masunaga, H., and Coauthors, 2010: Satellite data simulator unit: A multisensor, multispectral satellite simulator package. Bull. Amer. Meteor. Soc., 91, 1625-1632, https://doi.org/10.1175/ 2010BAMS2809.1.

Mlawer, E. J., S. J. Taubman, P. D. Brown, M. J. Iacono, and S. A. Clough, 1997: Radiative transfer for inhomogeneous atmospheres: RRTM, a validated correlated-k model for the longwave. J. Geophys. Res., 102, 16 663-16 682, https://doi.org/ 10.1029/97JD00237.

Ohno, T., and M. Satoh, 2015: On the warm core of a tropical cyclone formed near the tropopause. J. Atmos. Sci., 72, 551-571, https://doi.org/10.1175/JAS-D-14-0078.1.

Pendergrass, A. G., and H. E. Willoughby, 2009: Diabatically induced secondary flows in tropical cyclones. Part I: Quasisteady forcing. Mon. Wea. Rev., 137, 805-821, https://doi.org/ 10.1175/2008MWR2657.1.

Rotunno, R., and G. H. Bryan, 2012: Effects of parameterized diffusion on simulated hurricanes. J. Atmos. Sci., 69, 2284-2299, https://doi.org/10.1175/JAS-D-11-0204.1.

Stern, D. P., and D. S. Nolan, 2012: On the height of the warm core in tropical cyclones. J. Atmos. Sci., 69, 1657-1680, https:// doi.org/10.1175/JAS-D-11-010.1.

_- and F. Zhang, 2013a: How does the eye warm? Part I: A potential temperature budget analysis of an idealized tropical cyclone. J. Atmos. Sci., 70, 73-90, https://doi.org/10.1175/ JAS-D-11-0329.1.

— and - 2013b: How does the eye warm? Part II: Sensitivity to vertical wind shear and a trajectory analysis. J. Atmos. Sci., 70, 1849-1873, https://doi.org/10.1175/JAS-D-12-0258.1.

- , and 2016: The warm-core structure of Hurricane Earl (2010). J. Atmos. Sci., 73, 3305-3328, https://doi.org/10.1175/ JAS-D-15-0328.1.

Tang, B., and K. Emanuel, 2012: Sensitivity of tropical cyclone intensity to ventilation in an axisymmetric model. J. Atmos. Sci., 69, 2394-2413, https://doi.org/10.1175/JAS-D-11-0232.1. 
Tsuboki, K., and A. Sakakibara, 2002: Large-scale parallel computing of cloud resolving storm simulator. High Performance Computing, H. P. Zima et al., Eds., Springer, 243-259.

- - M. K. Yoshioka, T. Shinoda, M. Kato, S. Kanada, and A. Kitoh, 2015: Future increase of supertyphoon intensity associated with climate change. Geophys. Res. Lett., 42, 646-652, https://doi.org/10.1002/2014GL061793.

Tsujino, S., and H.-C. Kuo, 2020: Potential vorticity mixing and rapid intensification in the numerically simulated Supertyphoon Haiyan (2013). J. Atmos. Sci., 77, 2067-2090, https://doi.org/ 10.1175/JAS-D-19-0219.1.

_ , and K. Tsuboki, 2020: Intensity change of Typhoon Nancy (1961) during landfall in a moist environment over Japan: A numerical simulation with spectral nudging. J. Atmos. Sci., 77, 1429-1454, https://doi.org/10.1175/JAS-D-19-0119.1.

_, - _ , and H.-C. Kuo, 2017: Structure and maintenance mechanism of long-lived concentric eyewalls associated with simulated Typhoon Bolaven (2012). J. Atmos. Sci., 74, 3609-3634, https://doi.org/10.1175/JAS-D-16-0236.1.
Tsukada, T., and T. Horinouchi, 2020: Estimation of the tangential winds and asymmetric structures in typhoon inner core region using Himawari-8. Geophys. Res. Lett., 47, e2020GL087637, https://doi.org/10.1029/2020GL087637.

Yamada, H., and Coauthors, 2018: Double warm-core structure of Typhoon Lan (2017) as observed through upper-tropospheric aircraft reconnaissance during T-PARCII. 33rd Conf. on Hurricanes and Tropical Meteorology, Ponte Vedra, FL, Amer. Meteor. Soc., 8C.2, https://ams.confex.com/ams/ 33HURRICANE/webprogram/Paper339931.html.

Yang, Y.-T., H.-C. Kuo, E. A. Hendricks, and M. S. Peng, 2013: Structural and intensity changes of concentric eyewall typhoons in the western North Pacific basin. Mon. Wea. Rev., 141, 2632-2648, https://doi.org/10.1175/MWR-D-1200251.1.

Zhang, D.-L., and H. Chen, 2012: Importance of the upper-level warm core in the rapid intensification of a tropical cyclone. Geophys. Res. Lett., 39, L02806, https://doi.org/10.1029/ 2011GL050578. 